QA: NA

800-30R-HER0-00100-000

REV 002

March 2005

\title{
Concepts for Waste Retrieval and Alternate Storage of Radioactive Waste
}

Prepared for:

U.S. Department of Energy

Office of Civilian Radioactive Waste Management

Office of Repository Development

1551 Hillshire Drive

Las Vegas, NV 89134-6321

Prepared by:

Bechtel SAIC Company, LLC

1180 Town Center Drive

Las Vegas, Nevada 89144

Under Contract Number

DE-AC28-01RW12101 


\section{DISCLAIMER}

This report was prepared as an account of work sponsored by an agency of the United States Government. Neither the United States Government nor any agency thereof, nor any of their employees, nor any of their contractors, subcontractors or their employees, makes any warranty, express or implied, or assumes any legal liability or responsibility for the accuracy, completeness, or any third party's use or the results of such use of any information, apparatus, product, or process disclosed, or represents that its use would not infringe privately owned rights. Reference herein to any specific commercial product, process, or service by trade name, trademark, manufacturer, or otherwise, does not necessarily constitute or imply its endorsement, recommendation, or favoring by the United States Government or any agency thereof or its contractors or subcontractors. The views and opinions of authors expressed herein do not necessarily state or reflect those of the United States Government or any agency thereof. 
Concepts for Waste Retrieval and Alternate Storage of Radioactive Waste

Originator:
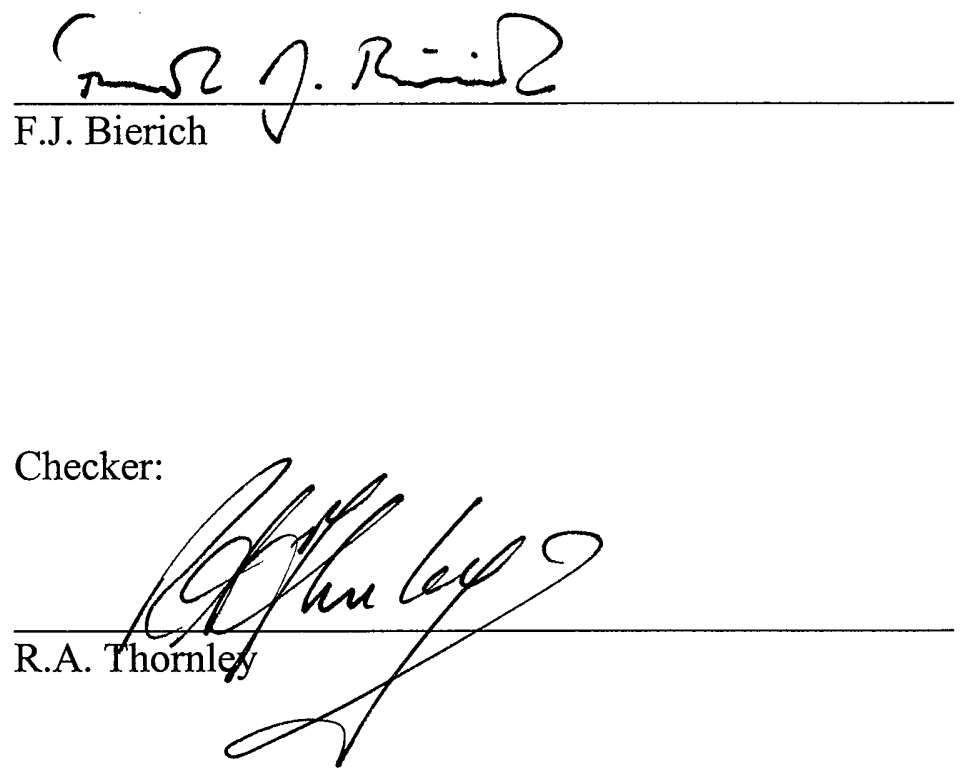

QER Checker:

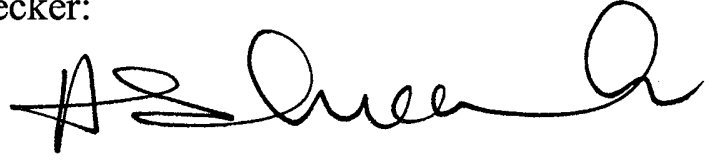

J. Oshikanlu

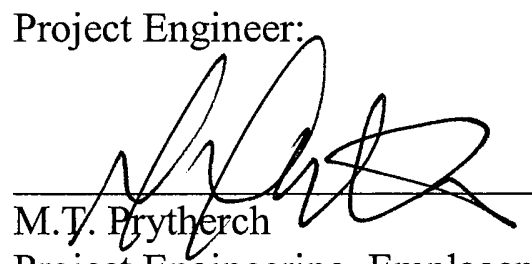

Project Engineering, Emplacement and Retrieval $\frac{\operatorname{man} 229,2005}{\text { Date }}$

$\frac{\text { MARl. 29. } 2005}{\text { Date }}$

Mendel 29,2005

Date

$\operatorname{maR} 29,2005$

800-30R-HER0-00100-000 REV 002

iii

March 2005 
INTENTIONALLY LEFT BLANK 


\section{CHANGE HISTORY}

\section{Revision}

Number

00

01

02

\section{Description of Change}

Initial issue

Changed discussion from multiple locomotives to a single locomotive. Made editorial changes throughout to address clarity and readability. Changed QA designator of the document. Updated to reflect changes in recovery strategies and concepts for off-normal retrieval. Revision bars identify changes.

Minor changes made to align document with SAR Section 1.11. Revision bars identify changes. References updated to current revisions. 


\section{INTENTIONALLY LEFT BLANK}




\section{CONTENTS}

CHANGE HISTORY ..V

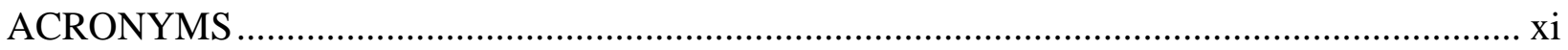

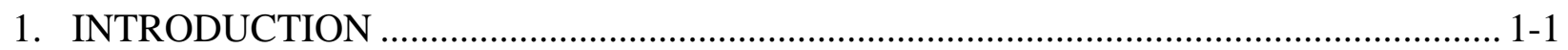

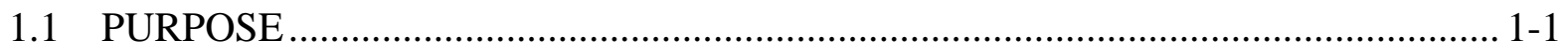

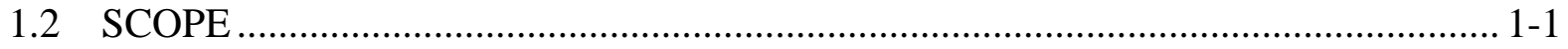

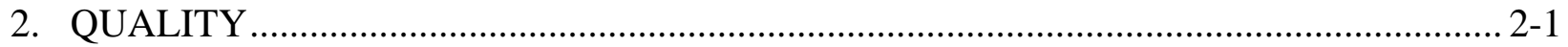

2.1 QUALITY ASSURANCE ............................................................................ 2-1

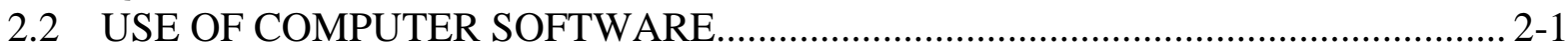

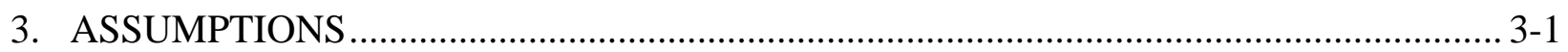

4. TIMELINE FOR RETRIEVAL ..................................................................................

4.1 WINDOW OF TIME TO INITIATE RETRIEVAL ………….................................. 4-1

4.2 DURATION OF THE RETRIEVAL PERIOD ............................................................ 4-1

5. ACCESS TO THE SUBSURFACE REPOSITORY ………......................................... 5-1

5.1 GENERAL DESCRIPTION OF THE SUBSURFACE REPOSITORY ...................... 5-1

5.2 EMPLACEMENT DRIFT PANEL DESCRIPTIONS ……….................................... 5-1

6. WASTE RETRIEVAL OPERATIONS......................................................................... 6-1

6.1 CONCEPT OF OPERATIONS FOR WASTE RETRIEVAL ..................................... 6-1

6.2 RETRIEVAL OPERATIONS .........................................................................

6.2.1 Preparatory Operations at Surface Facilities............................................... 6-1

6.2.2 Preparatory Subsurface Operations......................................................... 6-10

6.2.3 Waste Package Retrieval............................................................................ 6-12

6.2.4 System Interfaces ............................................................................. 6-18

6.2.5 Transport of Personnel and Maintenance Equipment to the Subsurface

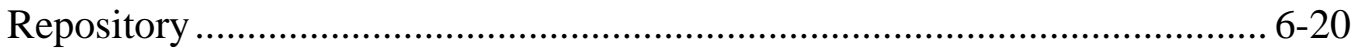

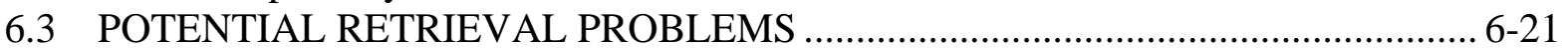

6.3.1 Repository Conditions ………………………..................................... 6-22

6.3.2 Contingency Measures................................................................................... 6-23

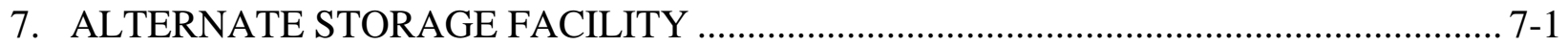

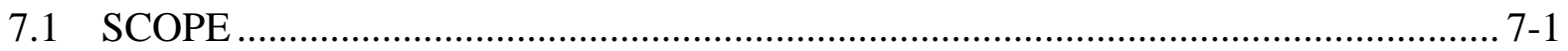

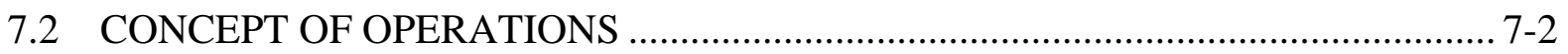

7.3 SITE LOCATION AND DESCRIPTION .........................................................

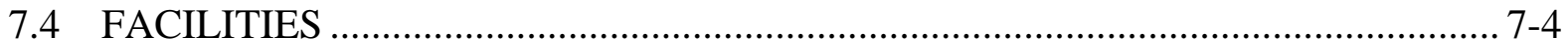

7.4.1 Alternate Storage Facility ……………………....................................... 7-4

7.4.2 Waste Retrieval Transfer Building ....................................................... 7-4

7.4.3 Concrete Storage Unit............................................................................... 7-8 


\section{CONTENTS (Continued)}

Page

8. RADIATION PROTECTION

8-1

8.1 RETRIEVAL OPERATION-HAZARDS ANALYSES AND PRECLOSURE SAFETY

8.2 ALTERNATE STORAGE FACILITY OPERATIONS-HAZARDS ANALYSES AND PRECLOSURE SAFETY ASSESSMENTS 8-1

8.3 OPERATION-OCCUPATIONAL DOSE ESTIMATES AND ENGINEERING AND ADMINISTRATIVE CONTROLS (ALARA IMPLEMENTATION)

9. COMPATIBILITY OF RETRIEVAL WITH RELATED REPOSITORY OPERATIONS. $9-1$

9.1 PERFORMANCE CONFIRMATION .................................................................. 9-1

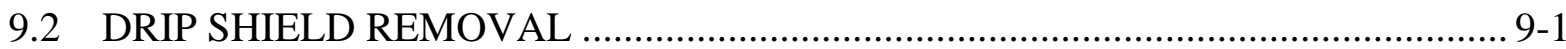

9.3 BACKFILLING OF EMPLACEMENT DRIFTS ................................................... 9-2

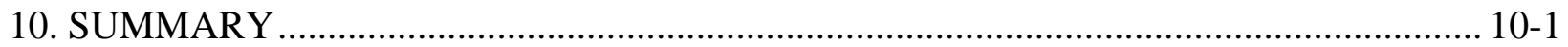

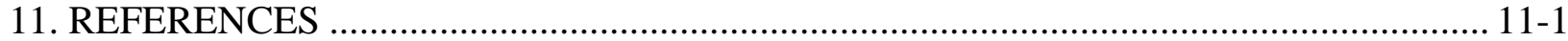

11.1 DOCUMENTS CITED .................................................................................. 11-1

11.2 CODES, STANDARDS, REGULATIONS, AND PROCEDURES ........................... 11-3 


\section{FIGURES}

Page

4-1. Retrieval Timeline …………........................................................................... 4-2

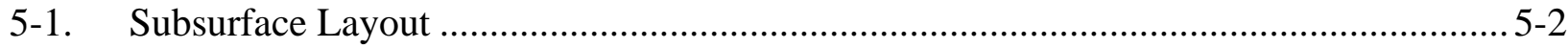

5-2. Panel 1 Layout ....................................................................................................... 5-3

5-3. Panel 2 Layout ...................................................................................................... 5-4

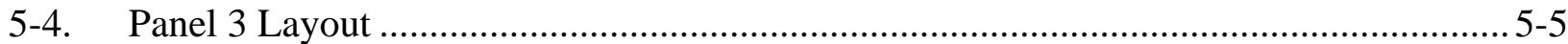

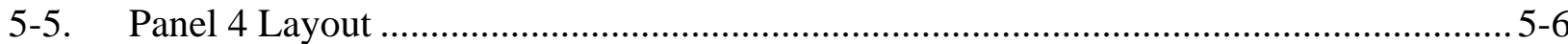

6-1. Emplacement Gantry, Pictorial View ………………................................................6-3

6-2. Waste Package Transporter, Pictorial View …………..................................................... 6-4

6-3. Transport Locomotive, Pictorial View …………….....................................................6-5

6-4. Gantry Carrier, Pictorial View .................................................................................. 6-6

6-5. Retrieval Equipment in Access Main ........................................................................ 6-7

6-6. Retrieval Equipment at Emplacement Transfer Dock ................................................... 6-13

6-7. Emplacement Drift and Gantry .............................................................................. 6-14

6-8. Waste Package Transporter with Waste Package on Pallet............................................ 6-16

6-9. $\quad$ Normal Retrieval Equipment and Sequence ……........................................................... 6-17

7-1. Possible Alternate Storage Facility, Scenario 1 Conceptual Design ................................. 7-3

7-2. Conceptual Operations Mechanical Flow, Scenario 1 Conceptual Design ....................... 7-5

7-3. Alternate Storage Facility Layout, Scenario 1 Conceptual Design ..................................... 7-6

7-4. Waste Retrieval Transfer Building, Scenario 1 Conceptual Design ................................... 7-7

7-5. Concrete Storage Unit, Scenario 1 Conceptual Design ..................................................... 7-9

7-6. Mobile Lifting Gantry, Scenario 1 Conceptual Design ............................................. 7-10

7-7. Modular Concrete Storage Pad, Scenario 1 Conceptual Design.................................... 7-11 


\section{INTENTIONALLY LEFT BLANK}




\section{ACRONYMS}

ALARA as low as is reasonably achievable

CCC central control center

CSU concrete storage unit

DOE U.S. Department of Energy

PLC programmable logic controller

NRC U.S. Nuclear Regulatory Commission

SSC structure, system, or component 


\section{INTENTIONALLY LEFT BLANK}




\section{INTRODUCTION}

\subsection{PURPOSE}

The primary purpose of this technical report is to present concepts for retrieval operations, equipment to be used, scenarios under which waste retrieval operations will take place, methods for responding to potential retrieval problems, and compliance with the preclosure performance objectives of 10 CFR 63.111(a) and (b) [DIRS 156605] during the retrieval of waste packages from the subsurface repository. If a decision for retrieval is made for any or all of the waste, the waste to be retrieved would be dispositioned in accordance with the regulations applicable at the time.

The secondary purpose is to present concepts for the design, construction, and operation of an alternate storage facility. The alternate storage facility would temporarily house the retrieved waste until final disposition is established. The concept presented is consistent with current practices and regulations for the protection of public health and safety and the environment, it demonstrates the feasibility of such a facility, if required, and it is based on the consideration for keeping radiation exposure as low as is reasonably achievable (ALARA).

\subsection{SCOPE}

The basis for this report is the assumption that retrieval can be generally conducted in a reversed order from emplacement (Assumptions, Section 3), using the same equipment. Consequently, the methods and procedures developed for the emplacement process are assumed to be applicable and are used for retrieval. The scope of this report is primarily limited to the consideration of retrieval under normal operating conditions. Off-normal recovery scenarios for individual waste packages or small numbers of waste packages are discussed only to illustrate that there are no foreseeable events that would prevent the retrieval of emplaced waste. The discussion of retrieval presented in this report is an adaptation of previous work and does not represent new technical analysis. The findings of those studies were considered in the development of the approaches presented in this report.

Recovery is used in this document to indicate the return from an off-normal condition to a normal operating regime. Retrieval is defined in 10 CFR 63.2 [DIRS 156605] and is used in this document as "the act of permanently removing radioactive waste from the underground location at which the waste had been previously emplaced for disposal.” Retrieval may be implemented on the basis of a policy decision to (non-inclusive): protect public health and safety, address environmental concerns, recover economically valuable constituents of the spent fuel or approach disposal in a different manner. Until a decision is made to permanently close the repository, the design must preserve the option to retrieve the emplaced nuclear waste as required in 10 CFR 63.111(e) [DIRS 156605]. The design approach to satisfy this requirement is that nothing in the repository design or the emplacement process shall preclude the retrieval of any or all waste packages. 


\section{INTENTIONALLY LEFT BLANK}




\section{QUALITY}

\subsection{QUALITY ASSURANCE}

This document was prepared in accordance with LP-3.11Q-BSC, Technical Reports. Although the retrieval subsystem, part of the emplacement and retrieval system, is classified as Safety Category in the Q-List (BSC 2005 [DIRS 171190]), this document does not contain information that is considered important to safety or important to waste isolation; therefore, this document is not subject to requirements of the Quality Assurance Requirements and Description (DOE 2004 [DIRS 171539]).

\subsection{USE OF COMPUTER SOFTWARE}

No computer software subject to LP-SI.11Q-BSC, Software Management, was used in the development of this document. Graphic figures are presented for illustrative purposes only and were not used for any computations. 


\section{INTENTIONALLY LEFT BLANK}




\section{ASSUMPTIONS}

The following assumptions have been established as the basis for this report:

1. Assumption: Drip shields, if installed before a decision to retrieve is made, can be removed by reversing the placement process. This is used in Section 9.2.

Basis: Drip shield removal would require the same type of mobile equipment and operations as used for placement in the emplacement drifts; removal should be a reversal of placement operations. The drip shield system has been designed so as not to preclude removal of the drip shield.

2. Assumption: Backfill, if placed in the emplacement drifts prior to a decision to retrieve, can be removed without affecting the retrieval schedule. This is used in Section 9.3.

Basis: The current design does not include backfill, and as such, an analysis of the backfill removal process has not been done. An analysis of backfill removal would be performed once the decision for waste retrieval has been made. Removal of the backfill from emplacement drifts could be accomplished without affecting the schedule by beginning backfill removal while the Alternative Storage Facility design and construction are underway. Additionally, backfill removal can take place in several drifts simultaneously.

3. Assumption: The waste retrieval process from the subsurface repository is the same as the emplacement process, but in reverse order. This is used in Sections 1.2 and 8.1.

Basis: Waste package removal would require the same type of mobile equipment and operations as used for transport and placement in the emplacement drifts; therefore, this process should be a reversal of operations. The waste emplacement system has been designed so that it does not preclude waste retrieval. 


\section{INTENTIONALLY LEFT BLANK}




\section{TIMELINE FOR RETRIEVAL}

\subsection{WINDOW OF TIME TO INITIATE RETRIEVAL}

The Code of Federal Regulations (10 CFR 63.111(e)(1)) [DIRS 156605] states that:

The geologic repository operations area must be designed to preserve the option of waste retrieval throughout the period during which wastes are being emplaced and thereafter, until the completion of a performance confirmation program and Commission review of the information obtained from such a program. To satisfy this objective, the geologic repository operations area must be designed so that any or all of the emplaced waste could be retrieved on a reasonable schedule starting at any time up to 50 years after waste emplacement operations are initiated, unless a different time period is approved or specified by the Commission. This different time period may be established on a case-by-case basis consistent with the emplacement schedule.

Currently, the design includes 50 years of forced ventilation following the completion of waste emplacement and prior to closure of the repository (BSC 2004 [DIRS 171541]). The 50-year ventilation period only applies to a $1.45 \mathrm{~kW} / \mathrm{m}$ thermal loading of the emplacement drifts. Different ventilation periods may be appropriate for different loading scenarios. Consequently, because the performance confirmation program will run through the period of forced ventilation, the option to retrieve must be preserved until the completion of the ventilation program (Williams 2003 [DIRS 166503]).

The current repository schedule shows that waste package emplacement will continue for 24 years after initiation. On this basis, the waste retrieval option must be preserved for an additional 50 years to complete the ventilation program. During this time, U.S. Nuclear Regulatory Commission (NRC) review of the performance confirmation information would occur.

The anticipated period of retrievability will extend until the decision is made to perform permanent closure. This period envelopes the 50-year period specified in 10 CFR 63.111(e)(1) [DIRS 156605] and is consistent with the 100-year maximum period required for retrieval equipment maintainability and replacement (BSC 2004 [DIRS 171599], Section 4.7.1.9).

\subsection{DURATION OF THE RETRIEVAL PERIOD}

The Code of Federal Regulations (10 CFR 63.111(e)(3)) [DIRS 156605] states that:

...a reasonable schedule for retrieval is one that would permit retrieval in about the same time as that required to construct the geologic repository operations area and emplace waste.

The current repository schedule shows a 2-year construction period after Construction Authorization is granted, followed by 24 years of emplacement, for a total of 26 years or approximately 30 years for planning purposes. Any new construction needed for retrieval would 
need to be completed in time to support completion of retrieval in a period approximately equivalent to the planned schedule for construction of the repository and emplacement of waste.

A timeline of retrieval activities is presented in Figure 4-1. This timeline reflects estimates of timeframes involved in the standard license amendment process with the engineering, procurement, and construction activities needed to support retrieval operations.

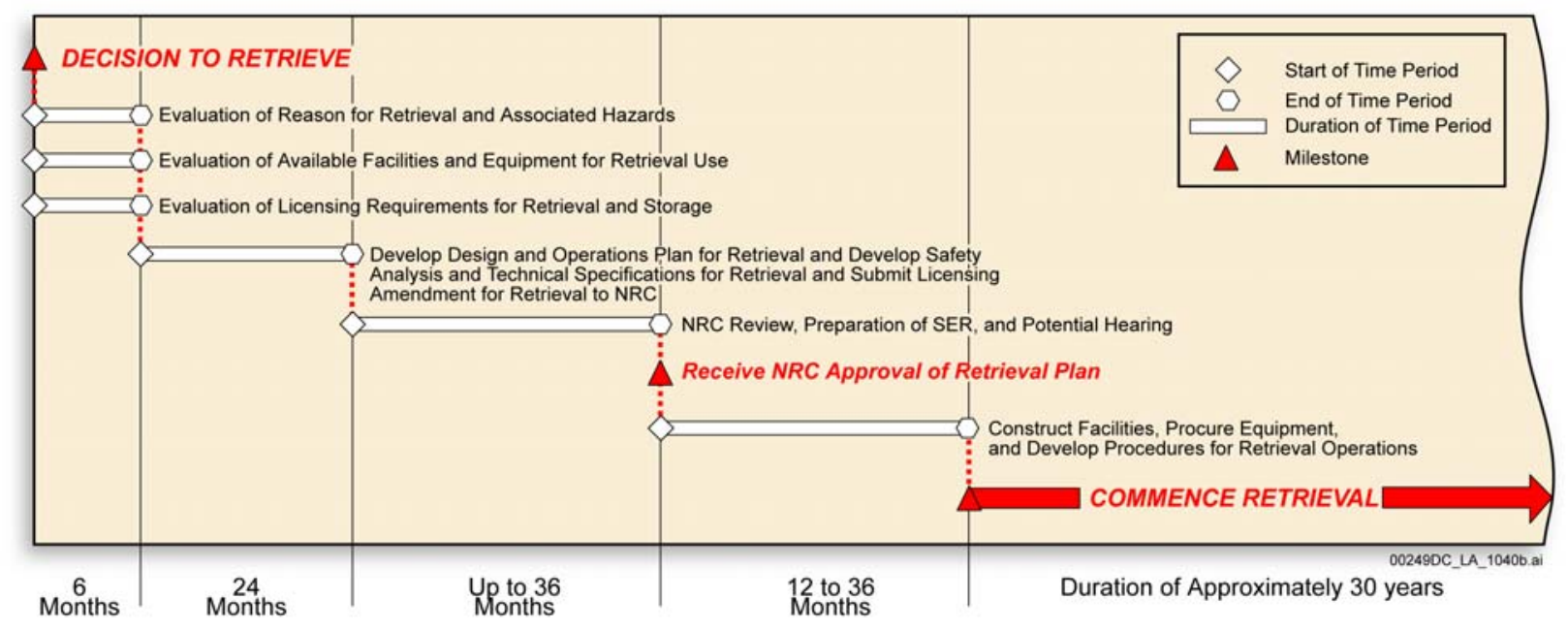

Figure 4-1. Retrieval Timeline 


\section{ACCESS TO THE SUBSURFACE REPOSITORY}

\subsection{GENERAL DESCRIPTION OF THE SUBSURFACE REPOSITORY}

The layout of the underground repository consists of four panels (Figure 5-1). These panels will accommodate 70,000 MTHM of spent nuclear fuel and high-level radioactive waste. Access to the individual emplacement drifts for each panel is discussed in the following section.

Access to the subsurface repository starts with the North Portal (Figure 5-1) and the north ramp that leads to the access mains and the individual emplacement drifts in each drift panel. All waste package transportation for waste retrieval will be through the North Portal, north ramp, and connecting access mains. The south ramp and the north construction ramp are used for construction and ventilation, but not for waste retrieval.

The panels are to be constructed sequentially in the order numbered (e.g., Panel 1 will be constructed first and Panel 4 will be the last to be constructed). As the drifts within each panel are completed, emplacement will follow in the same order.

\subsection{EMPLACEMENT DRIFT PANEL DESCRIPTIONS}

The initial emplacement will be in Panel 1, located within the central section of the overall layout (Figure 5-1). The size of Panel 1 is relatively small in comparison to the other panels in the repository. The path to the emplacement drifts for waste emplacement and retrieval equipment will be through the north ramp and the Panel 1 access main (Figure 5-2).

Panel 2 is located to the south of Panel 1. Layout details of Panel 2 are illustrated in Figure 5-3. Entry to the emplacement drifts for waste emplacement and retrieval will be through the Panel 1 access main to the Panel 2 access main.

Panel 3, located to the north of Panel 1, is divided into two zones, the east and west. Layout details of Panel 3 are illustrated in Figure 5-4. Entry to the emplacement drifts for waste emplacement and retrieval will be through the Panel 3 access main.

Panel 4 is located to the west of Panel 3. Layout details of Panel 4 are illustrated in Figure 5-5. Entry to the emplacement drifts for waste emplacement and retrieval will be through the Panel 1 access main to the Panel 4 access main. 


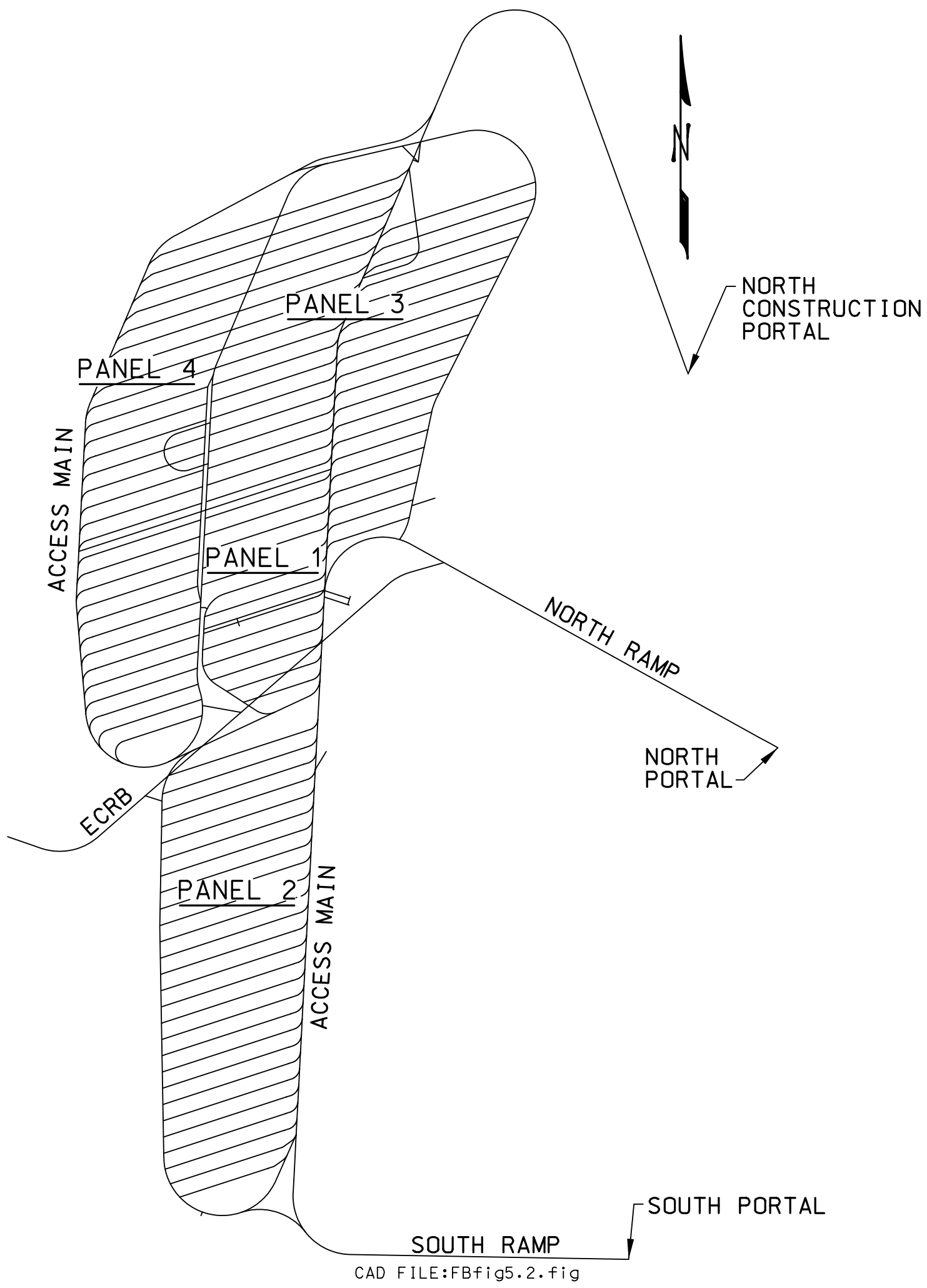

Source: BSC 2003 [DIRS 165572], Figure 5.

Figure 5-1. Subsurface Layout 


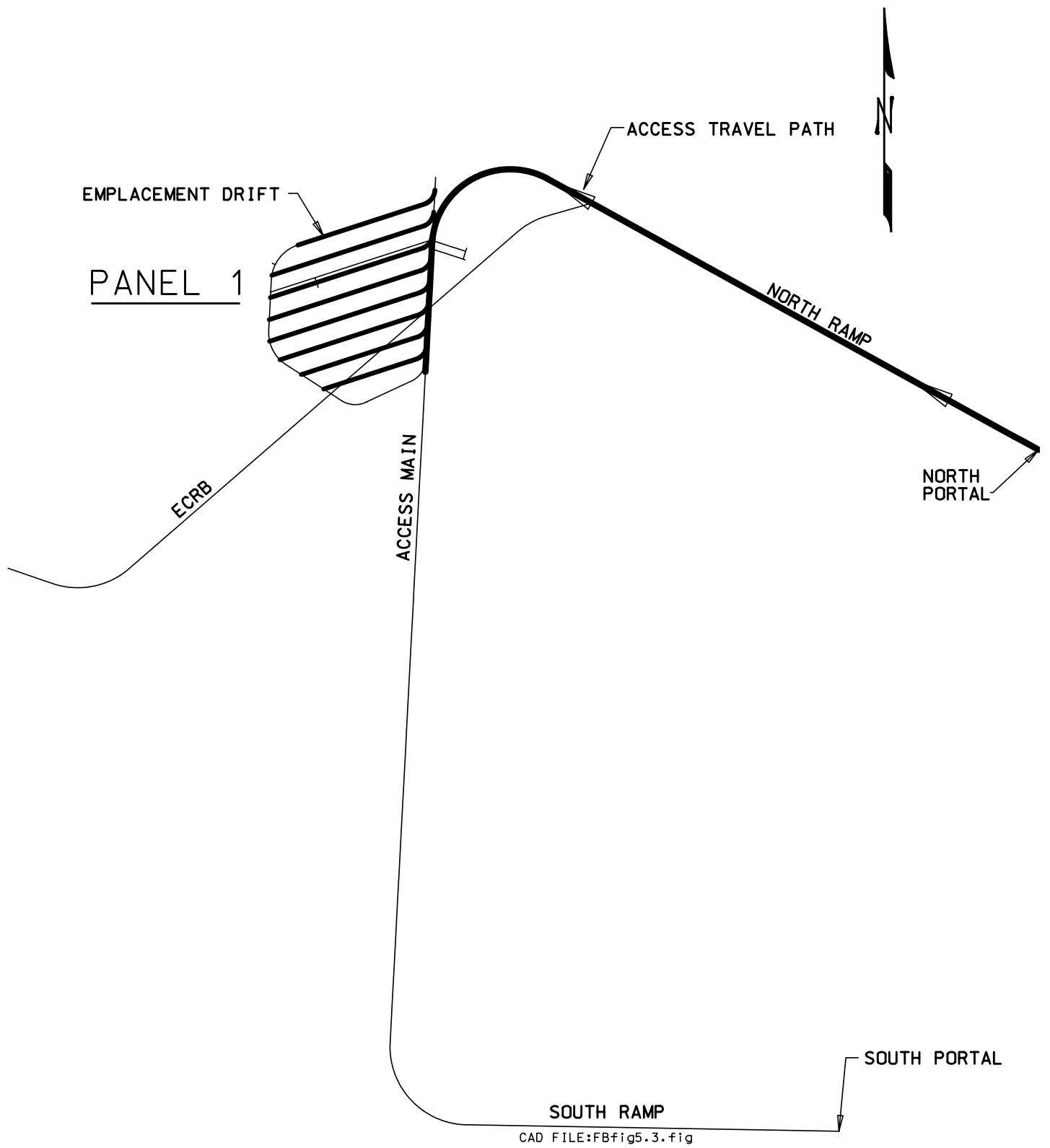

Source: BSC 2003 [DIRS 165572], Figure 5.

Figure 5-2. Panel 1 Layout 


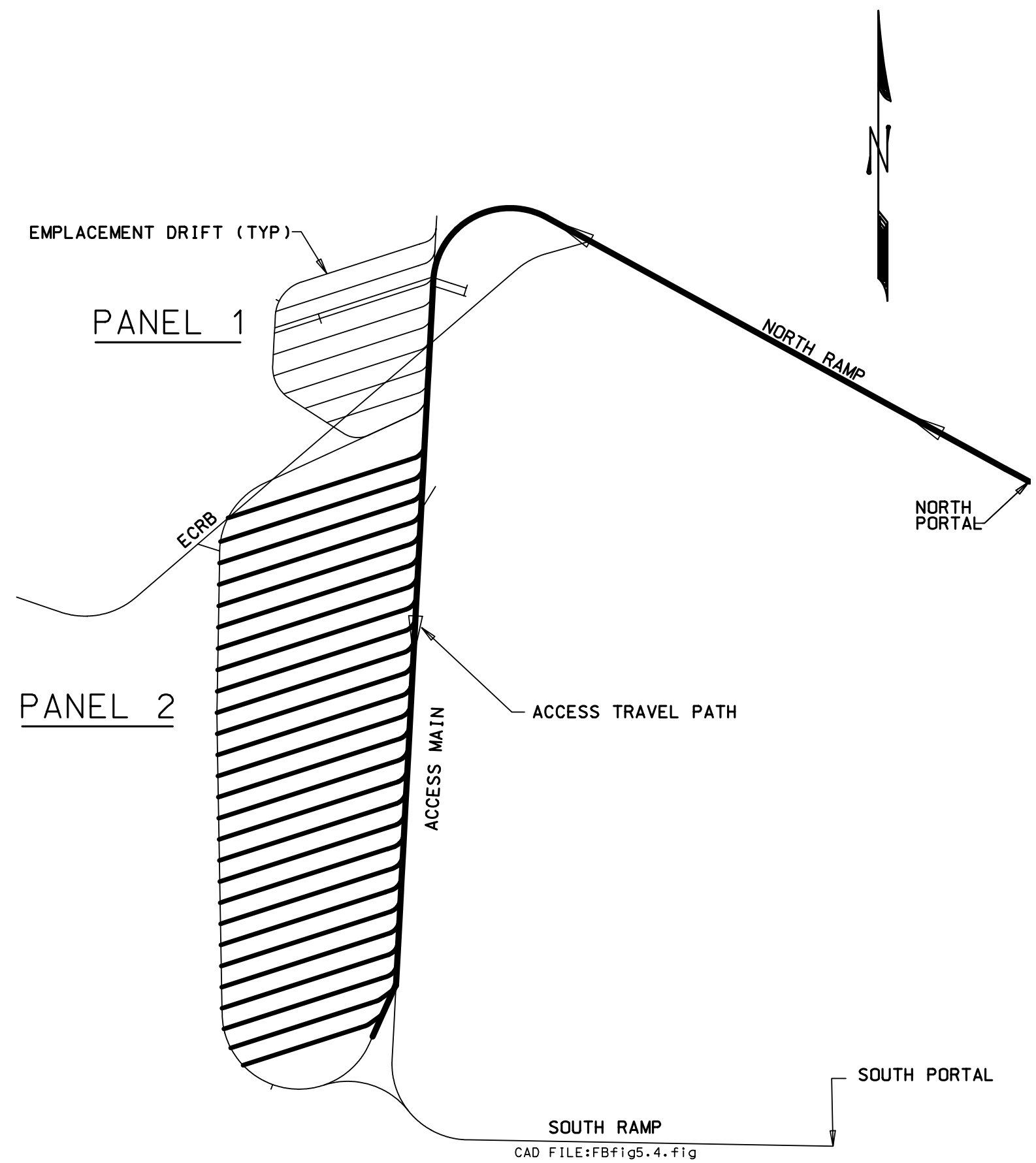

Source: BSC 2003 [DIRS 165572], Figure 5.

Figure 5-3. Panel 2 Layout 


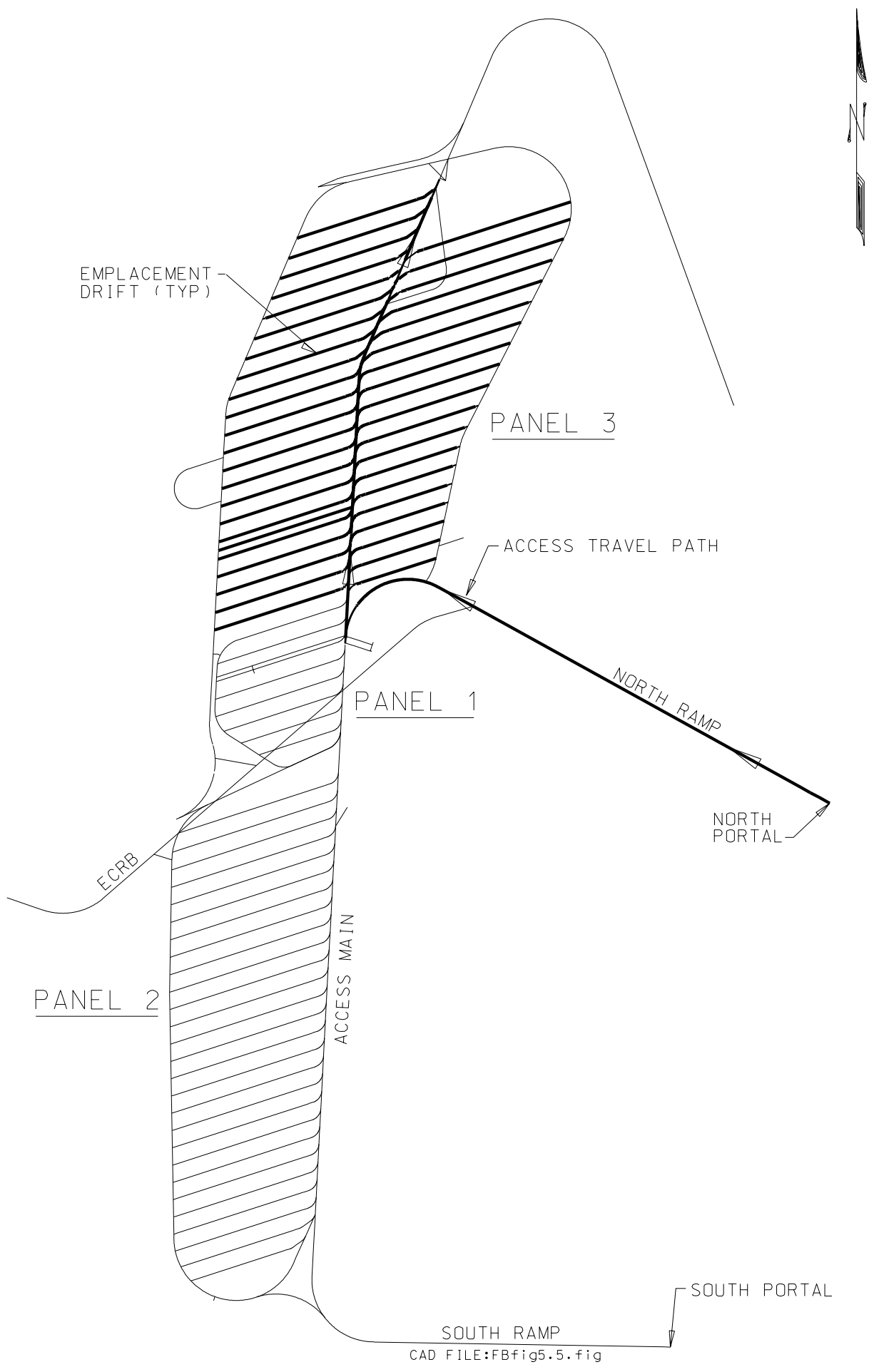

Source: BSC 2003 [DIRS 165572], Figure 5.

Figure 5-4. Panel 3 Layout 


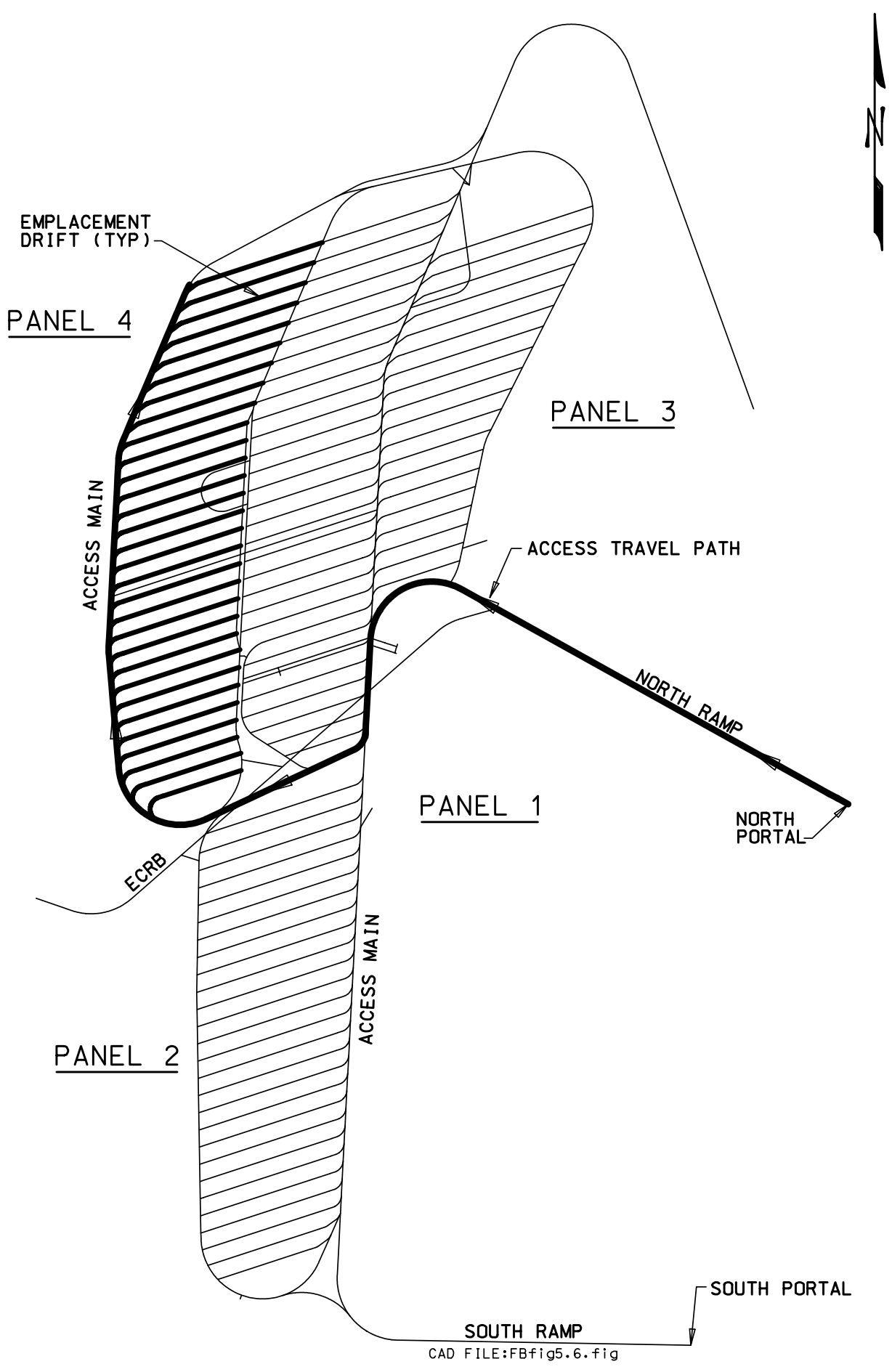

Source: BSC 2003 [DIRS 165572], Figure 5.

Figure 5-5. Panel 4 Layout 


\section{WASTE RETRIEVAL OPERATIONS}

\subsection{CONCEPT OF OPERATIONS FOR WASTE RETRIEVAL}

Conditions within the repository during the preclosure period are expected to be normal, that is, systems, structures, and components (SSCs) function as designed under operational conditions. SSCs that make up the subsurface facility would be operating normally and capable of performing in accordance with the intended functions. The operational concept for retrieving waste packages would be to perform the steps executed in the waste emplacement process in reverse order. Operational interferences that may be expected are the same as those encountered during emplacement operations. Off-normal conditions, if any, will require an assessment to identify specific conditions and determine an appropriate retrieval strategy.

\subsection{RETRIEVAL OPERATIONS}

\subsubsection{Preparatory Operations at Surface Facilities}

The preparatory surface operations necessary to support the waste retrieval process are discussed in this section. Included are descriptions of maintenance activities for the mobile equipment. Formal maintenance plans will be developed during detail design to address each aspect of waste retrieval operations in a manner that will protect health and safety and keep radiation exposures at ALARA levels.

Major mobile equipment to support waste retrieval includes the waste package emplacement gantry (Figure 6-1), the waste package transporter (Figure 6-2), transport locomotive(s) (Figure 6-3), and the gantry carrier (Figure 6-4 and 6-5).

The waste package emplacement gantry is a rail-based vehicle that operates in the emplacement drifts. The gantry can lift the waste package and associated emplacement pallet, move them within the emplacement drifts, and lower them onto the waste package transporter for waste retrieval.

The waste package transporter is a railcar that transports waste packages individually in a radiation-shielded enclosure from the subsurface facility to the surface facilities.

The transport locomotive moves the waste package transporter between the subsurface and surface facilities. The transport locomotive also moves the gantry carrier, as required, between emplacement drifts and between the subsurface facility and the surface facilities.

The gantry carrier is a railcar used to transport the waste package emplacement gantry between emplacement drifts and between the subsurface facilities and the surface facilities.

\subsubsection{Preparation of Waste Package Emplacement Gantry for Waste Retrieval}

Under the current retrieval concept, the waste package emplacement gantry is one of the most critical elements in the overall design for waste package retrieval. It is essential that this equipment perform the intended functions in a safe and reliable manner. The waste package emplacement gantry has been designed to operate in the relatively harsh thermal and radiation 
environment inside the emplacement drifts. Due to these harsh conditions, human operators located at the central control center (CCC), or similar facility, will control the operations of the waste package emplacement gantry. The basic purpose of the waste package emplacement gantry is to transport the waste packages from the emplacement transfer dock, along the length of the emplacement drift, and to emplace them within the drift. To support waste retrieval operations, the waste package emplacement gantry will also be capable of reversing this process.

A preliminary design of the waste package emplacement gantry (Figure 6-1) has been presented in Emplacement Gantry Design Calculation (BSC 2004 [DIRS 167425]).

One option to be considered is the use of multiple emplacement gantries operating underground at the same time in different drifts. When emplacement gantries are not in use in the emplacement drifts, it is anticipated that they will be housed in a support facility on the surface where routine maintenance will be performed to ensure the gantries remain operational.

Routine maintenance activities could include:

1. Lubrication of ball screws, gear reducers, bearings, and similar items

2. Checking motor operation

3. Truck, wheel, and drive system maintenance

4. Calibration of instrumentation

5. Verification of control system operation

6. Repair or replacement of cameras and communications equipment.

These activities will be completed on a scheduled basis, determined during the detailed design and fabrication of the emplacement gantries.

The surface facility used for maintenance will contain a dock and rail system of appropriate rail gage, similar to the emplacement transfer dock located at each emplacement drift. This will allow the gantries to be loaded and unloaded from the gantry carrier. Control of the waste package emplacement gantry functions can be accomplished using the same wireless methods that will be used in the emplacement drifts or by directly connecting a temporary pendant to the gantry control system. When it is determined that a waste package emplacement gantry is ready to be used in the subsurface repository, it will be moved to the dock and transferred to the gantry carrier.

The gantry carrier (Figure 6-4) is a flatbed rail car that will shuttle the waste package emplacement gantry between the surface facility and the emplacement drifts. The gantry carrier will also be used to move the waste package emplacement gantry from one drift to another. Similar functions will be performed for the drip shield emplacement gantry. The transport locomotive will be used to move the gantry carrier. Maintenance activities, similar to those described above for the emplacement gantry, will be performed for the gantry carrier. 


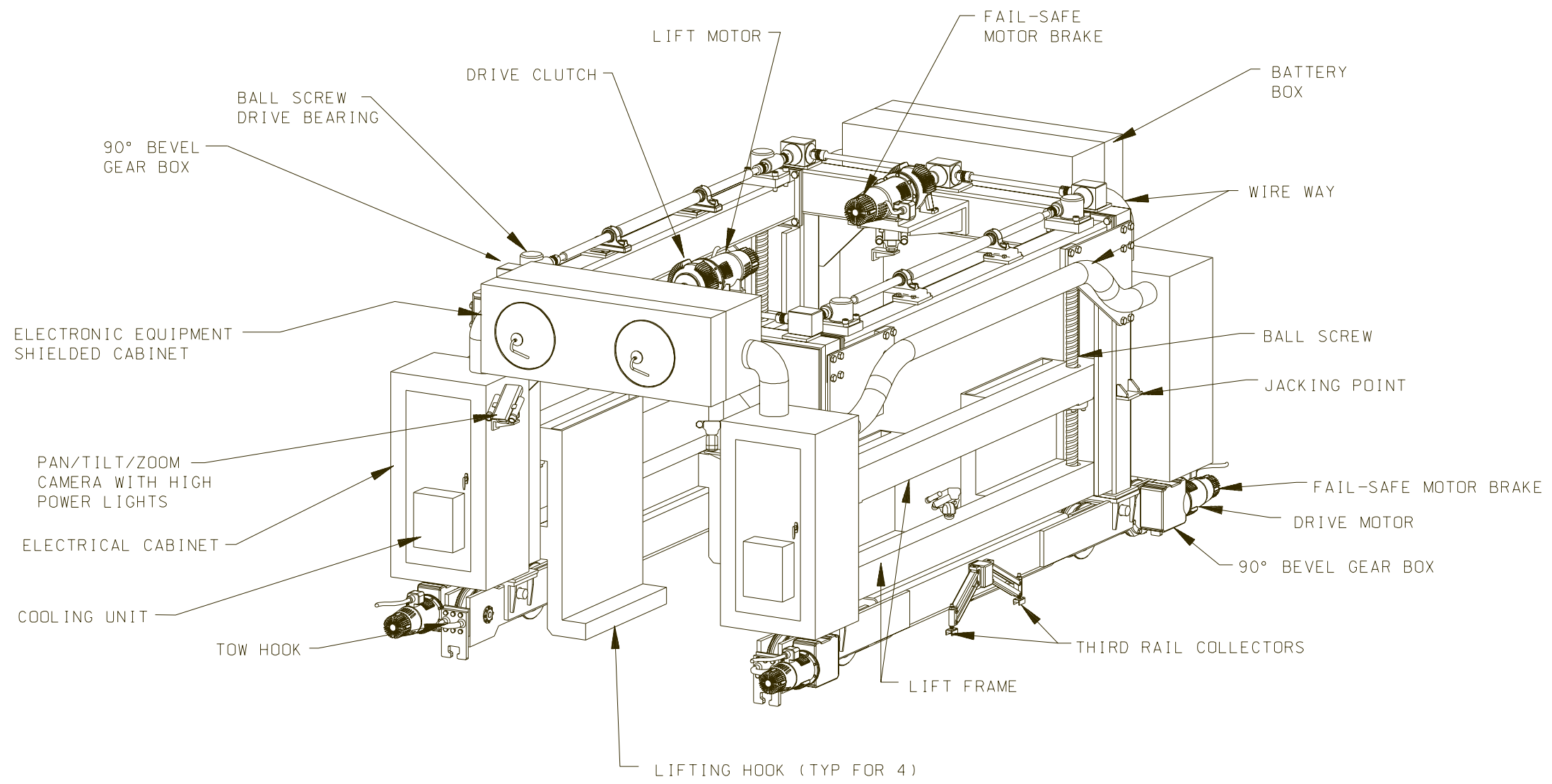

Source: adapted from BSC 2004 [DIRS 169002].

Figure 6-1. Emplacement Gantry, Pictorial View 


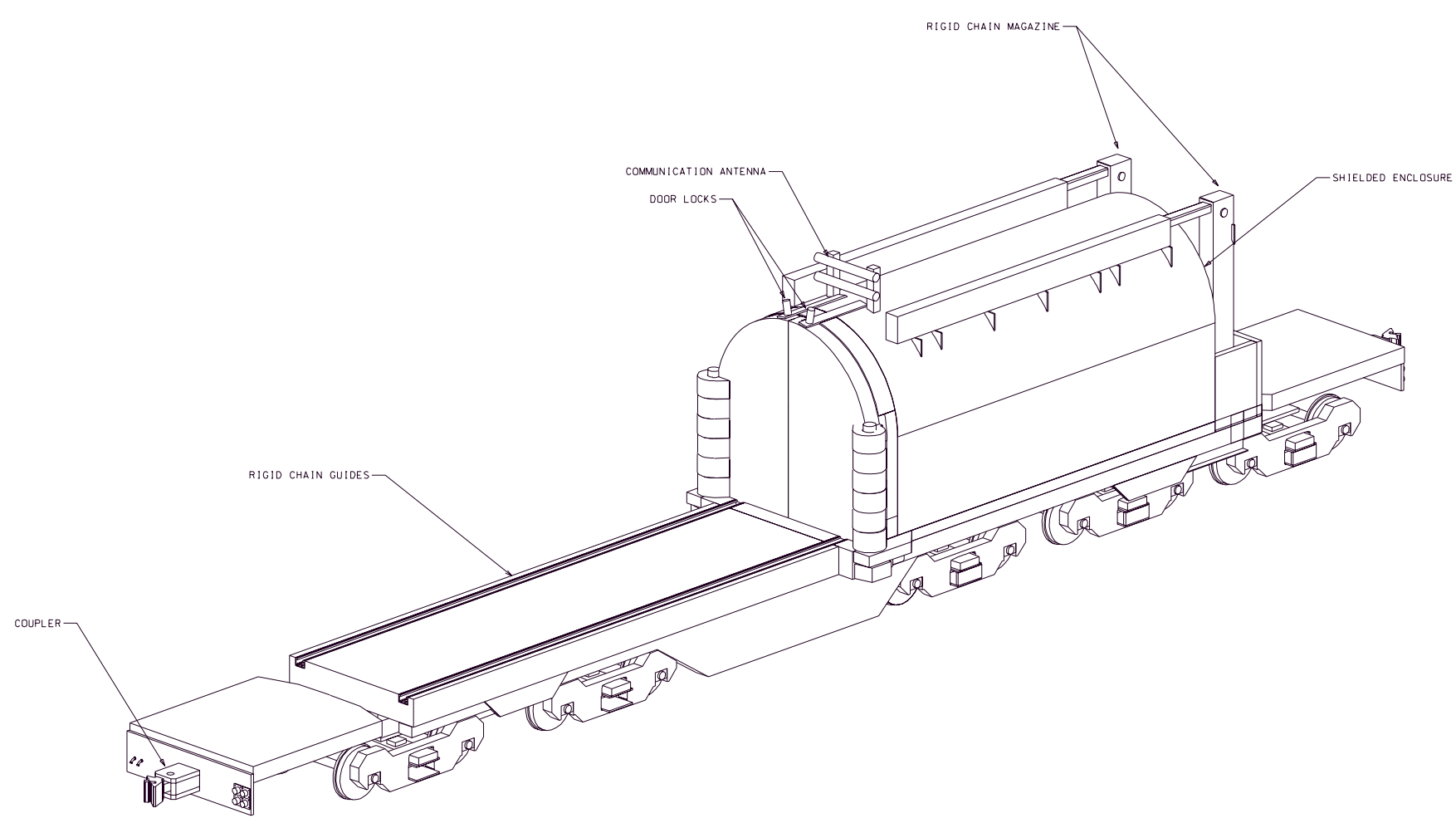

Source: adapted from BSC 2001 [DIRS 154553].

Figure 6-2. Waste Package Transporter, Pictorial View 


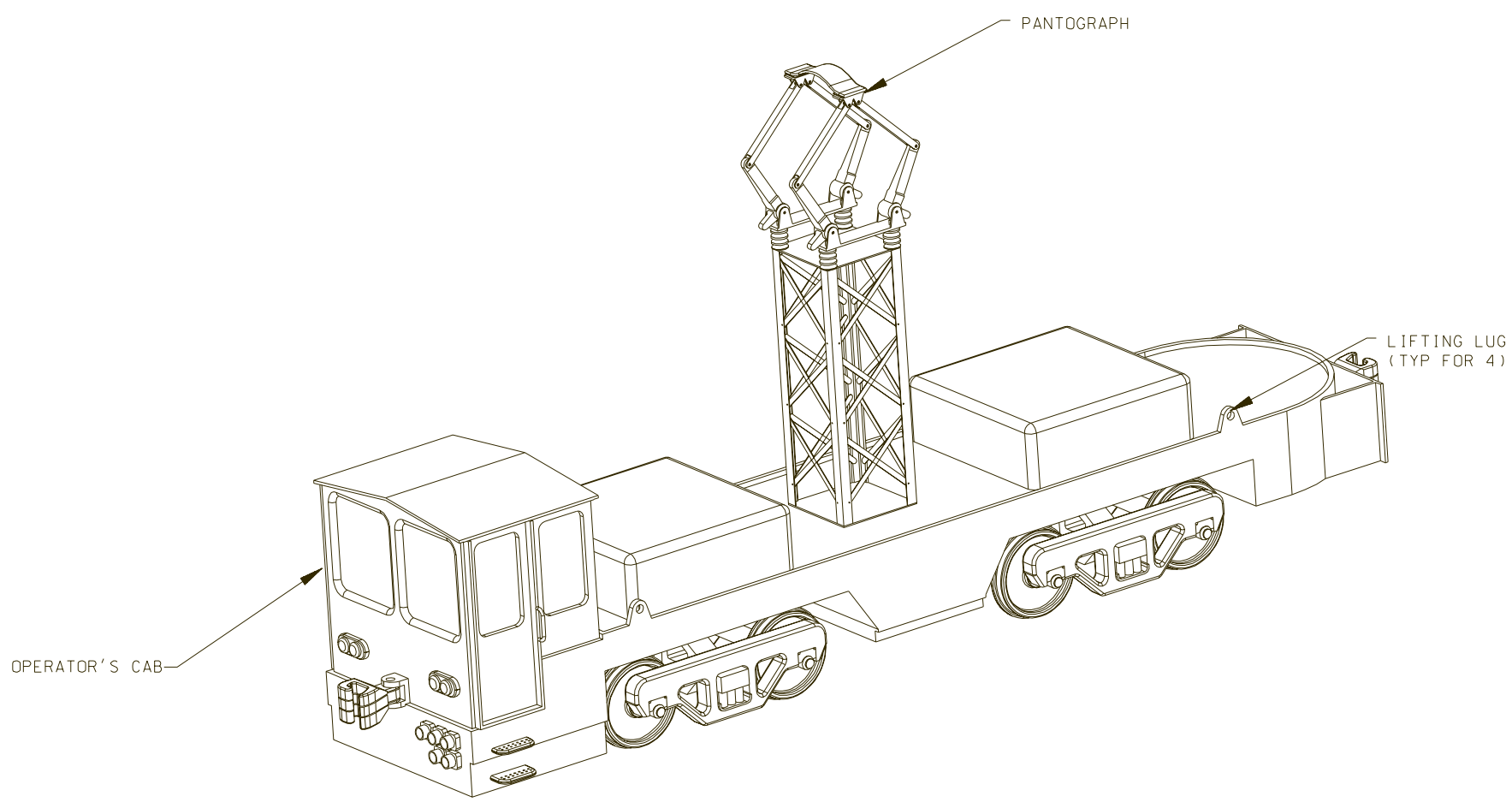

Source: adapted from BSC 2001a [DIRS 155732].

Figure 6-3. Transport Locomotive, Pictorial View 


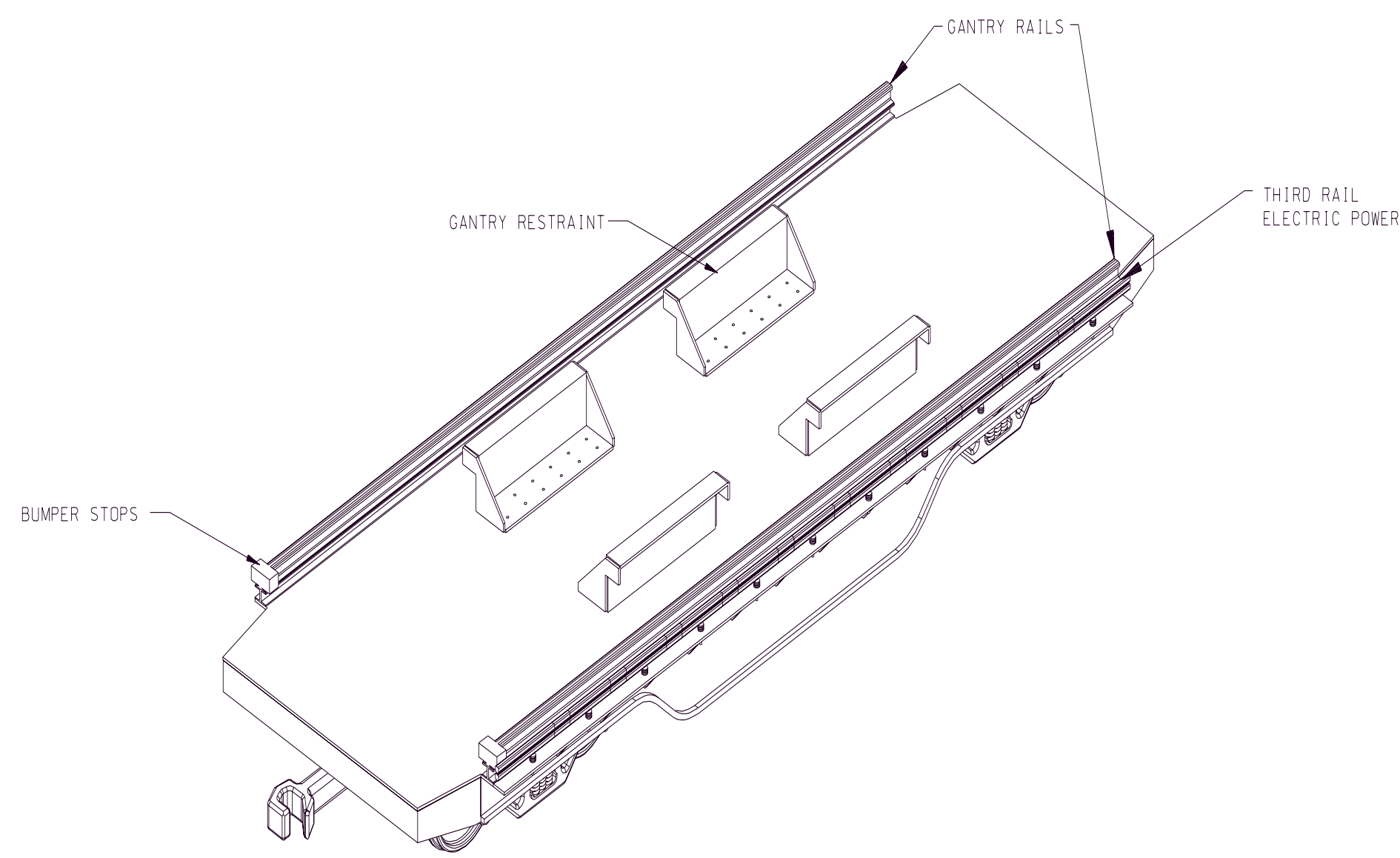

Source: adapted from BSC 2001 [DIRS 154553].

Figure 6-4. Gantry Carrier, Pictorial View 


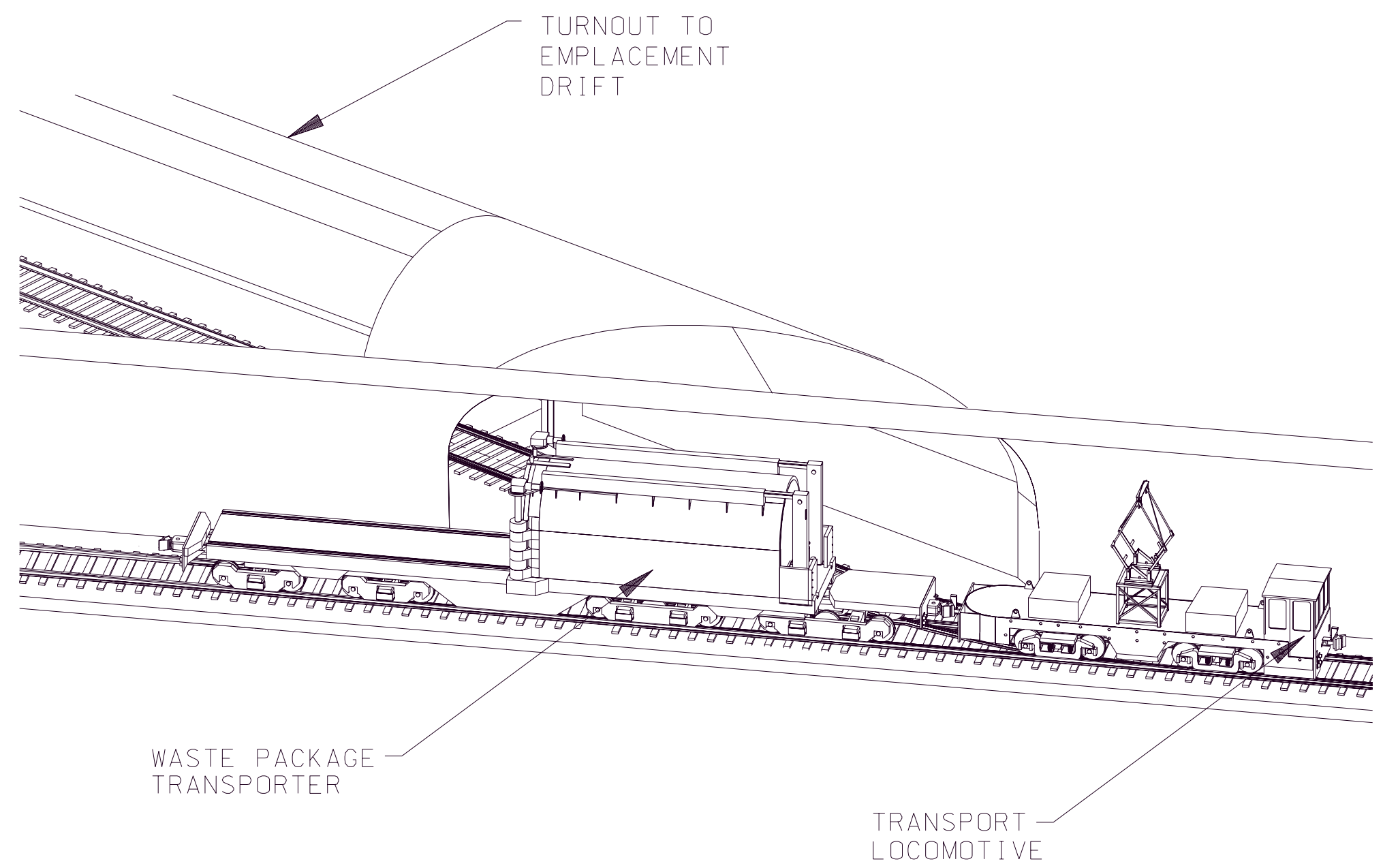

Source: adapted from DOE 2002 [DIRS 155943].

Figure 6-5. Retrieval Equipment in Access Main 


\subsubsection{Preparation of the Waste Package Transporter for Waste Retrieval}

The waste package transporter is a rail car that will be used to transport waste packages in a completely enclosed and shielded enclosure. Transport operations will start with the emplacement gantry lowering the retrieved waste package and emplacement pallet onto the waste package transporter at the emplacement transfer dock. A preliminary mechanical design for the waste package transporter was presented in the Gantry Structural/Control System Analysis (BSC 2001 [DIRS 154553]) and the Waste Package Transporter Design Calculation (BSC 2004 [DIRS 167428]), as illustrated in Figure 6-2. The waste package transporter carries the waste package in a shielded enclosure to protect personnel that may need to work in the area through which the transporter will travel. In the current design configuration, the shielding used to form the walls, floor, crown, and doors of the waste package enclosure on the waste package transporter will consist of multiple layers of stainless and carbon steels and a borated polyethylene material.

The waste package transporter will be equipped with air brakes and a backup set of spring-loaded fail-safe brakes. The shielded enclosure on the waste package transporter will have double doors at one end that will be opened and closed by heavy-duty gear motors mounted in-line with the axis of the door hinges. A bedplate and rigid-chain drive system will be used for extending and retracting the bedplate during loading and unloading activities. Both of these systems will have multiple positioning sensors and other types of performance feedback sensors. A camera system for remote viewing, along with radiation and thermal monitoring instrumentation, will be provided on the waste package transporter.

The loading and unloading functions of the waste package transporter will be remotely controlled. Control commands will originate from operators on the locomotive or from personnel at the CCC. In either case, a programmable logic controller (PLC)-based control system on the transport locomotive will process the control signals. Signals are then transferred to a PLC-based control system on the waste package transporter. The PLC-based control system on the waste package transporter would then open or close the doors, extend or retract the bedplate, lock the bedplate during transit, and monitor the interior environment while a waste package is present. Interface with the surface facilities will be through the transport locomotive control system. The PLC on the locomotive will be used to monitor and check operations and system performance parameters of the waste package transporter and relay these signals to personnel at the CCC.

To meet the peak retrieval rates, two or more waste package transporters may be in operation at a time. When the waste package transporters are not in use, it is anticipated that they will be housed in a surface facility where routine maintenance will be performed to ensure they remain operational.

Routine maintenance activities could include:

1. Lubrication of the bedplate mechanism, gear reducers, bearings, and similar items

2. Checking door operation and proper sealing

3. Truck and wheel system maintenance

4. Calibration of instrumentation 
5. Verification of control system operation

6. Repair or replacement of cameras and communications equipment.

These activities will be completed on a scheduled basis, determined during the detailed design and fabrication of the waste package transporters.

\subsubsection{Preparation of the Transport Locomotive for Waste Retrieval}

Transport locomotives will serve as the multi-purpose prime mover of equipment and personnel and will be used in almost every aspect of subsurface operations. During retrieval operations, transport locomotives will be used to move waste packages (individually in waste package transporters) from the emplacement drifts to the surface facilities. Transport locomotives will also be used to shuttle waste package emplacement gantries from drift to drift and periodically return them to the surface. In addition, transport locomotives will be used to move personnel and materials within the subsurface operations area.

Current concepts for the transport locomotive (Figure 6-3) are based on commercially available mining locomotives. Electric power for the locomotive will be provided by an overhead catenary system, and the locomotive will be designed for direct manual control and wireless remote control (BSC 2001 [DIRS 155732], Section 3.3.1.3).

The transport locomotive will engage with the gantry carrier and the waste package transporter by use of an automatic coupler. These couplers will join automatically and can be released by means of an air cylinder that can be activated from the compressed air system on the locomotive. It is envisioned that the automatic couplers will include the mechanical coupling as well as other required utilities such as compressed air, electrical power, and connections for the control system. Sensors in the coupler will transmit control signals to the control system on the locomotive indicating proper engagement.

To take a waste package emplacement gantry to the subsurface repository, the transport locomotive will engage the gantry carrier in the surface facilities. The gantry will have to be properly orientated on the carrier so that it can be readily unloaded at the emplacement transfer dock. The locomotive and gantry carrier will then travel to the North Portal, through the north ramp and access main, to a designated emplacement drift.

To take a waste package transporter to the subsurface repository, the transport locomotive will engage the waste package transporter in the surface facility. The locomotive will engage the end of the transporter with the shielded enclosure, leaving the open deck end uncoupled. The locomotive communication and control interface with the transporter will be used to verify that the transporter:

- Door can be opened and closed

- Bedplate can be extended and retracted

- Monitoring and communication signals can be received by the locomotive.

After successful operation of mechanical and monitoring functions, the locomotive and transporter will be considered ready for waste transport and waste retrieval. 
To meet the peak retrieval rates, two or more transport locomotives may operate at a time. When transport locomotives are not in use, it is anticipated that they will be housed in a support facility on the surface where routine maintenance will be performed to ensure they remain operational.

Routine maintenance activities could include:

1. Lubrication of gear reducers, bearings, and similar items

2. Checking motor operation

3. Truck, wheel, and drive system maintenance

4. Calibration of instrumentation

5. Verification of control system operation

6. Repair or replacement of cameras and communications equipment.

\subsubsection{Preparation of the Transport Locomotive and Waste Package Transporter for Retrieval}

After unloading a retrieved waste package at the surface facility, the waste package transporter will be readied for the retrieval and transportation of the next waste package. The bedplate of the transporter will be retracted into the shielded enclosure and the shielded enclosure doors will be closed. The locomotive and transporter will then exit the surface facility.

Orientation of the waste package transporter must be accomplished prior to entering the repository as the waste package transporter and locomotive cannot rotate or change orientation after they enter the subsurface facility. The open deck of the waste package transporter must ultimately face the emplacement transfer dock for successful transfer of the waste package from the emplacement drift. After successfully orienting the waste package transporter using the surface rail spurs, operators will drive the locomotive to the North Portal where final readings and inspections can take place prior to descending the north ramp.

\subsubsection{Preparatory Subsurface Operations}

Necessary preparatory subsurface operations prior to waste retrieval are discussed in this section.

\subsubsection{Waste Package Emplacement Gantry Placement}

\subsection{Transfer of the Waste Package Emplacement Gantry from Surface Facilities to an Emplacement Drift}

A transport locomotive will engage a gantry carrier in the surface facility. The waste package emplacement gantry will be loaded, positioned, and secured on the carrier for transport to a designated emplacement drift. Operators in the cab of the locomotive will then drive the locomotive with gantry carrier to the North Portal, ensuring that the locomotive and gantry carrier are properly oriented to effect transfer of the gantry to the emplacement transfer dock. After appropriate check-in procedures are completed at the North Portal, the operators will drive the locomotive down the north ramp of the repository. Status and position signals will be continuously transmitted to personnel in the CCC who remotely monitor the operation. The operators will then drive the locomotive to the turnout at the designated emplacement drift. 
Locomotive operators would then switch the control system to remote, leave the locomotive, and move to a low-dose waiting area, avoiding potentially high radiation areas. Exactly how far away the low-dose waiting area may be will be determined on the basis of final calculations of the expected dose in the waiting area (calculated with the emplacement access doors open and closed). In the low-dose waiting area, the operators would inform CCC personnel that it is clear to complete the gantry unloading operation. CCC personnel would now control the locomotive. The emplacement access doors would be opened and the locomotive would slowly push the gantry carrier into the turnout of the emplacement drift. After the locomotive passes, the emplacement access doors would be closed. Video signals and sensory signals would be conveyed to the personnel in the CCC to allow them to complete the docking of the gantry carrier at the emplacement transfer dock. After alignment and other appropriate signals indicating correct docking have been received, the emplacement gantry would be driven off the gantry carrier into the emplacement drift under control of CCC personnel.

After the gantry is in the emplacement drift and correct operation has been verified, the locomotive and gantry carrier would move away from the emplacement transfer dock through the turnout. The emplacement access doors would be opened to allow passage and then closed as the locomotive and gantry carrier passed into the access main. At this time, CCC personnel would notify the locomotive operators in the low dose waiting area that it was safe to return to the cab of the locomotive. The locomotive operators would then switch control of the locomotive to manual, and they would resume control of the locomotive. The locomotive and gantry carrier would then be returned to the surface facility where the gantry carrier would be uncoupled and stored for the next gantry transfer.

\subsection{Transfer of the Waste Package Emplacement Gantry between Emplacement Drifts or to the Surface Facilities}

When the waste package emplacement gantry has completed retrieval operations in an emplacement drift, or if maintenance is required, it will be necessary to remove the waste package emplacement gantry from the current emplacement drift. This can be accomplished by reversing the steps described in Section 6.2.2.1.1, as follows.

The locomotive operators would drive the locomotive and gantry carrier to the turnout, switch the locomotive to remote control, and move to a low-dose waiting area. The emplacement access doors would open and the gantry carrier would be positioned at the emplacement transfer dock. The waste package emplacement gantry would be driven onto the deck of the gantry carrier. When the gantry is properly secured to the gantry carrier, the locomotive would back away from the emplacement transfer dock. The emplacement access doors would be closed after the locomotive and gantry carrier have passed. The operators would then return to the cab of the locomotive in the access main and drive the locomotive with the gantry carrier to the surface or to the turnout of another emplacement drift. If the gantry is taken to another turnout, then the subsurface sequence (Section 6.2.2.1.1) will be repeated. If it goes to the surface facility, appropriate checkout routines will be conducted at the North Portal, and the gantry would be transported to a surface facility for storage or maintenance. 


\subsection{Locomotive and Waste Package Transporter Travel into Subsurface Repository}

Waste packages must be transported between the subsurface repository and the surface facilities in a shielded waste package transporter that provides radiation protection to nearby workers and the environment.

After final check-in procedures are completed at the North Portal, the waste package transporter and transport locomotive (Figure 6-5) will be driven down the north ramp. Status and position signals will be continuously transmitted to the CCC for remotely monitoring the operation. Operators in the locomotive cab will control the locomotive functions. The operators will drive the locomotive to the designated emplacement drift where waste retrieval is scheduled.

In the access main, at a location near the designated turnout, the locomotive operators would stop the locomotive and switch the control system to remote. The operators would then leave the locomotive and move to a low-dose waiting area, avoiding potentially high radiation areas. Exactly how far away the low-dose waiting area may be will be determined on the basis of final calculations of the expected dose in the waiting area (calculated with the emplacement access doors open and closed). In the low-dose waiting area, the operators would inform CCC personnel that it is clear to complete the waste package transporter docking operation. CCC personnel would now control the locomotive coupled to the waste package transporter.

The locomotive, under remote control, pushes the waste package transporter, open deck end first, into the turnout to a point outside the emplacement access doors and stops. The emplacement access doors would be opened. When the operators in the CCC receive verification that the doors are completely open, the locomotive would slowly push the waste package transporter into the turnout. After the locomotive passes, the emplacement access doors are closed. Video signals along with sensory signals would be conveyed to the CCC personnel to allow them to safely complete the docking of the waste package transporter at the emplacement transfer dock (Figure 6-6). After alignment and other appropriate signals signifying correct docking have been received, the transporter shielded doors are opened and the waste package transporter bedplate is extended from the shielded enclosure for receipt of a retrieved waste package and emplacement pallet from the waste package emplacement gantry.

Appropriate sensory and visual equipment will inform CCC operators that the waste package transporter is ready for transport of the waste package and emplacement pallet.

\subsubsection{Waste Package Retrieval}

Normal waste retrieval would be the reverse of the basic emplacement operations. Waste retrieval would start with the transport of a waste package emplacement gantry to a pre-selected emplacement drift. Waste retrieval operations from the emplacement drifts to the surface facilities are described in this section. 


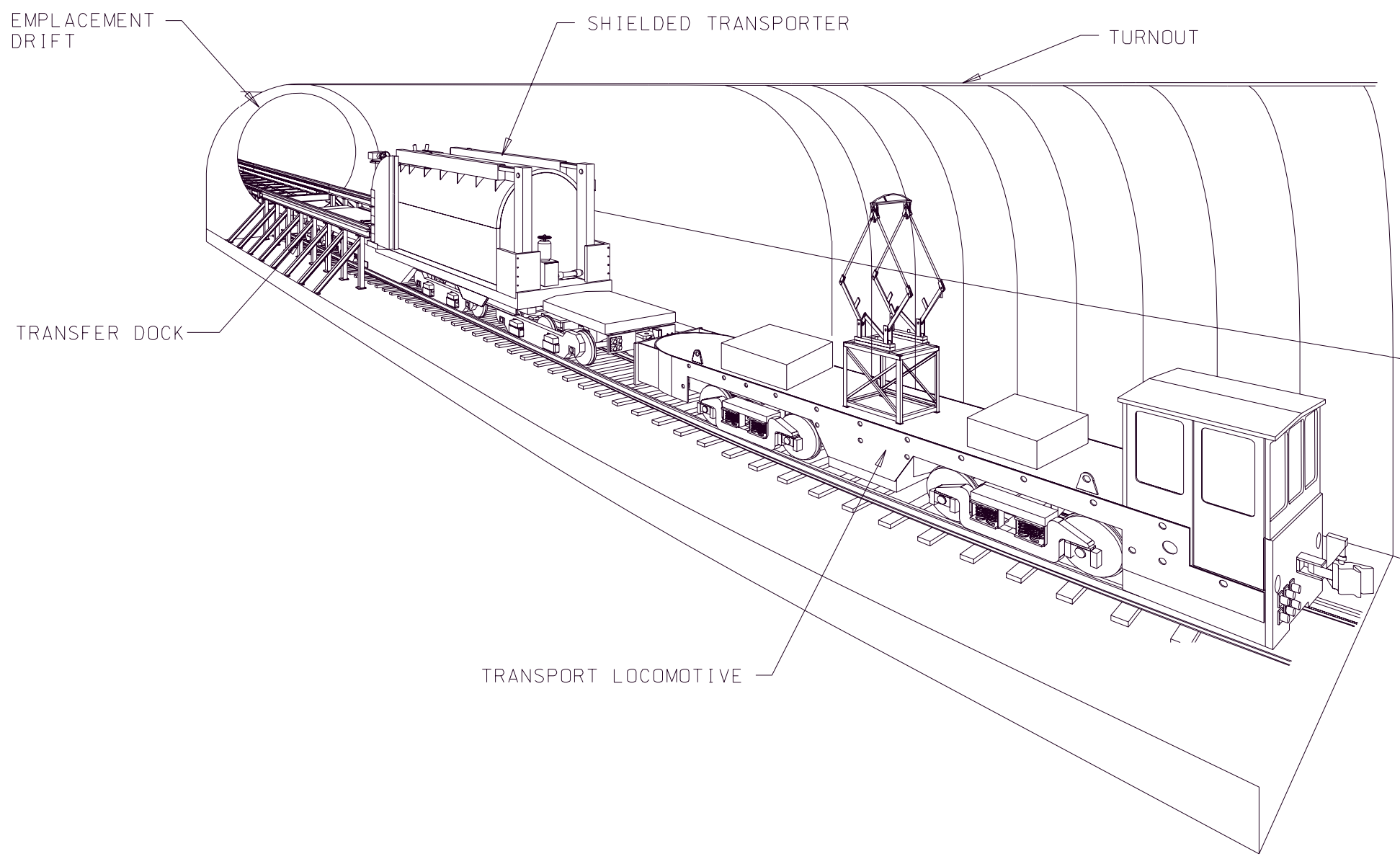

Source: adapted from BSC 2001 [DIRS 154553].

Figure 6-6. Retrieval Equipment at Emplacement Transfer Dock 


\subsubsection{Delivery of Retrieved Waste Package to the Emplacement Transfer Dock}

Typical waste package retrieval would start with the removal of the waste package emplaced nearest the emplacement drift turnout. CCC operators would direct the waste package emplacement gantry to the waste package to be removed. The unloaded gantry would be moved to the waste package with the lifting hooks in the low position. This condition facilitates the proper positioning of the gantry near the waste package for contact and engagement with the emplacement pallet. When the gantry and lifting hooks are aligned with the four contact points on the emplacement pallet, the lifting hooks will then be activated to make contact with the pallet and lift the waste package and emplacement pallet off the emplacement drift invert. After confirming that the waste package has been adequately raised, the gantry will then return to the emplacement transfer dock to unload the waste package and emplacement pallet onto the extended bedplate of the waste package transporter. A waste package emplacement gantry inside an emplacement drift with a retrieved waste package and pallet is illustrated in Figure 6-7.

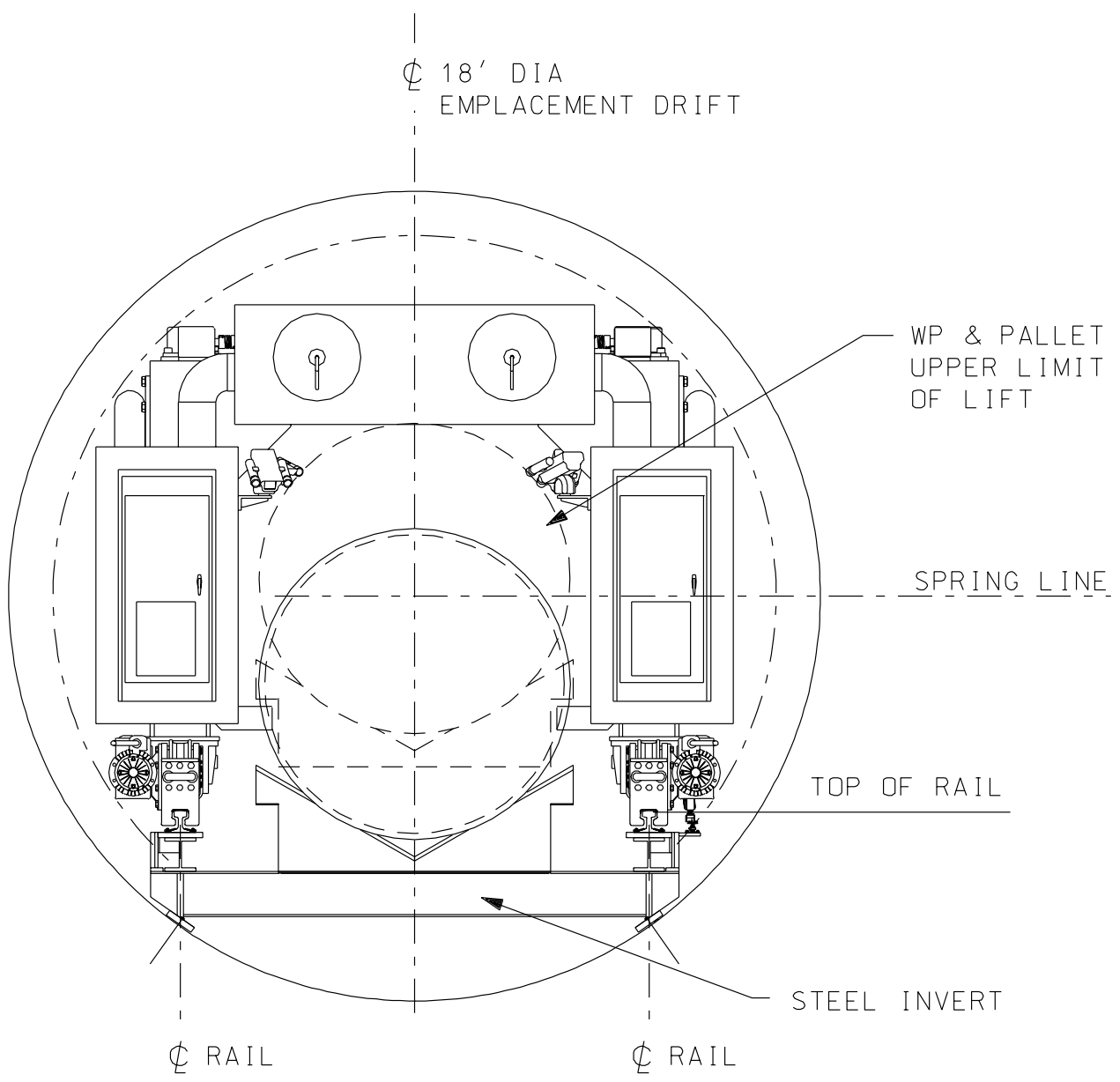

Source: adapted from BSC 2004 [DIRS 167425].

NOTE: $W P=$ waste package.

Figure 6-7. Emplacement Drift and Gantry 


\subsubsection{Placement of Retrieved Waste Package onto the Waste Package Transporter}

After arriving at the emplacement transfer dock, the gantry with the retrieved waste package and emplacement pallet would straddle the unshielded portion of the waste package transporter with the extended bed-plate. When in the proper position relative to the transporter, the gantry would lower the waste package and emplacement pallet onto the bedplate. The lifting hooks would be lowered far enough to clear and disengage from the emplacement pallet. The emplacement gantry would then move back into the emplacement drift.

A waste package transporter with a retrieved waste package and pallet on the extended bedplate is illustrated in Figure 6-8. The bedplate of the waste package transporter will be retracted into the shielded enclosure, and the waste package transporter doors will be closed. The transport locomotive will then pull the waste package transporter away from the emplacement transfer dock of the emplacement drift and the emplacement access doors will be opened and closed to allow equipment passage. Major operational handling steps and related mobile equipment for waste package retrieval are illustrated in Figure 6-9.

\subsubsection{Transport of the Retrieved Waste Packages to the Surface}

Under remote control by the CCC operators, the transport locomotive and waste package transporter will be directed from the turnout to the access main. The locomotive operators will then return from the low-dose waiting area and enter the cab of the locomotive.

The locomotive operators will set the transport locomotive controls back to manual and drive the waste package transporter and transport locomotive through the access main, up the north ramp, and through the North Portal to the surface. The rail layout, as part of the surface facility, will allow re-orientation of the waste package transporter, if necessary.

\subsubsection{Delivery of Retrieved Waste Package to the Surface Facility}

Upon reaching the appropriate surface facility, the locomotive operators switch control of the transport locomotive from manual to remote. The operators leave the locomotive and CCC personnel take over for all follow-on functions and the unloading functions at the surface facility.

As the transport locomotive and waste package transporter near the Waste Retrieval Transfer Building (Section 7.4.2), the access door opens to let the transport locomotive and waste package transporter enter. The locomotive will push the leading front end of the waste package transporter toward the waste package transfer dock. When in contact with the dock, the brakes of the locomotive and the transporter are engaged to prevent unintended movement. The shielded access door will then be closed to permit unloading of the waste package and emplacement pallet.

The shielding doors on the waste package transporter are opened, and the bedplate with the waste package and emplacement pallet is extended out of the shielded enclosure. When fully exposed on the unshielded transporter section, the waste package and emplacement pallet are lifted off of the waste package transporter (the concept of operations in the surface facility is described in Section 7.2). 


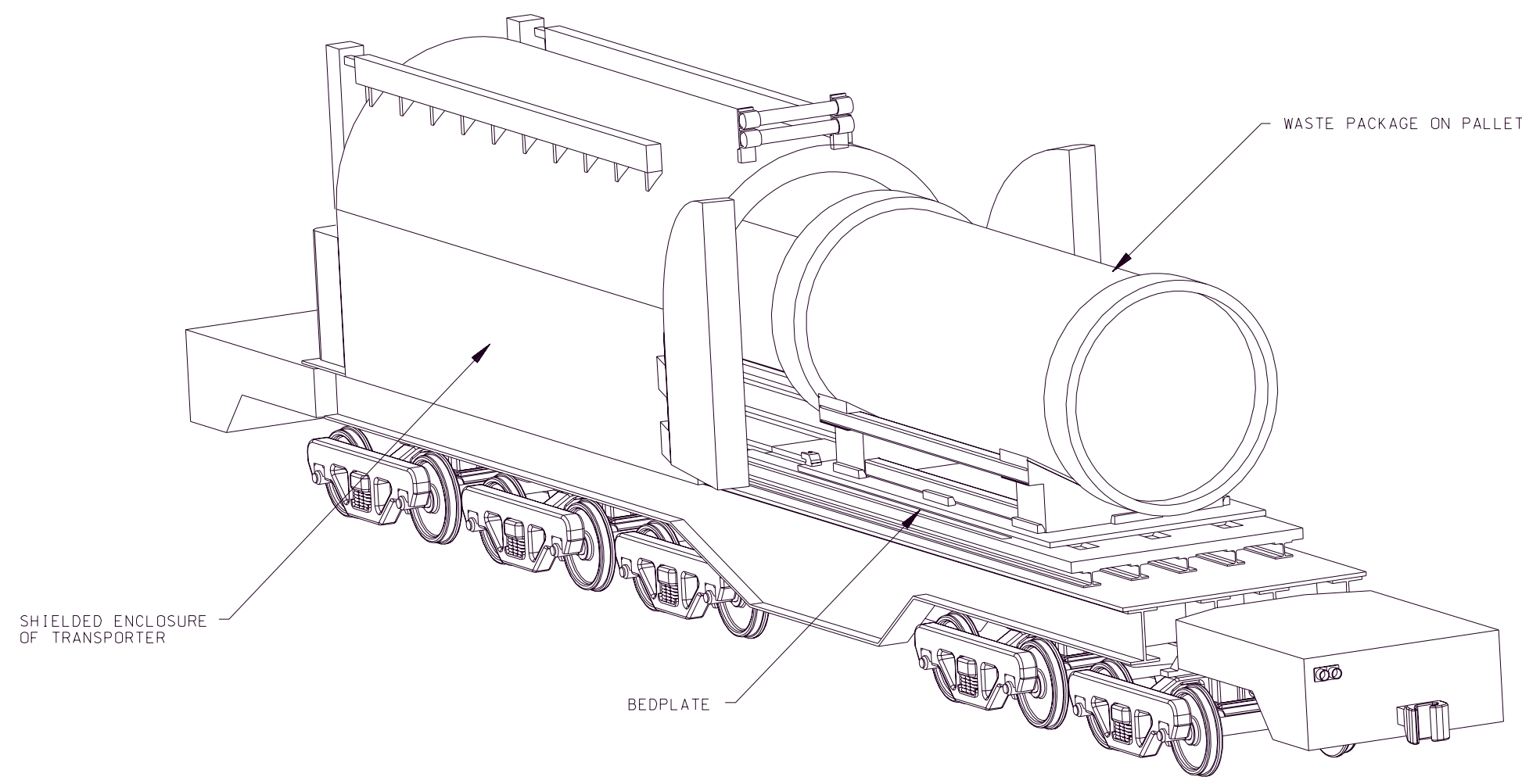

Source: adapted from DOE 2002 [DIRS 155943].

Figure 6-8. Waste Package Transporter with Waste Package on Pallet 

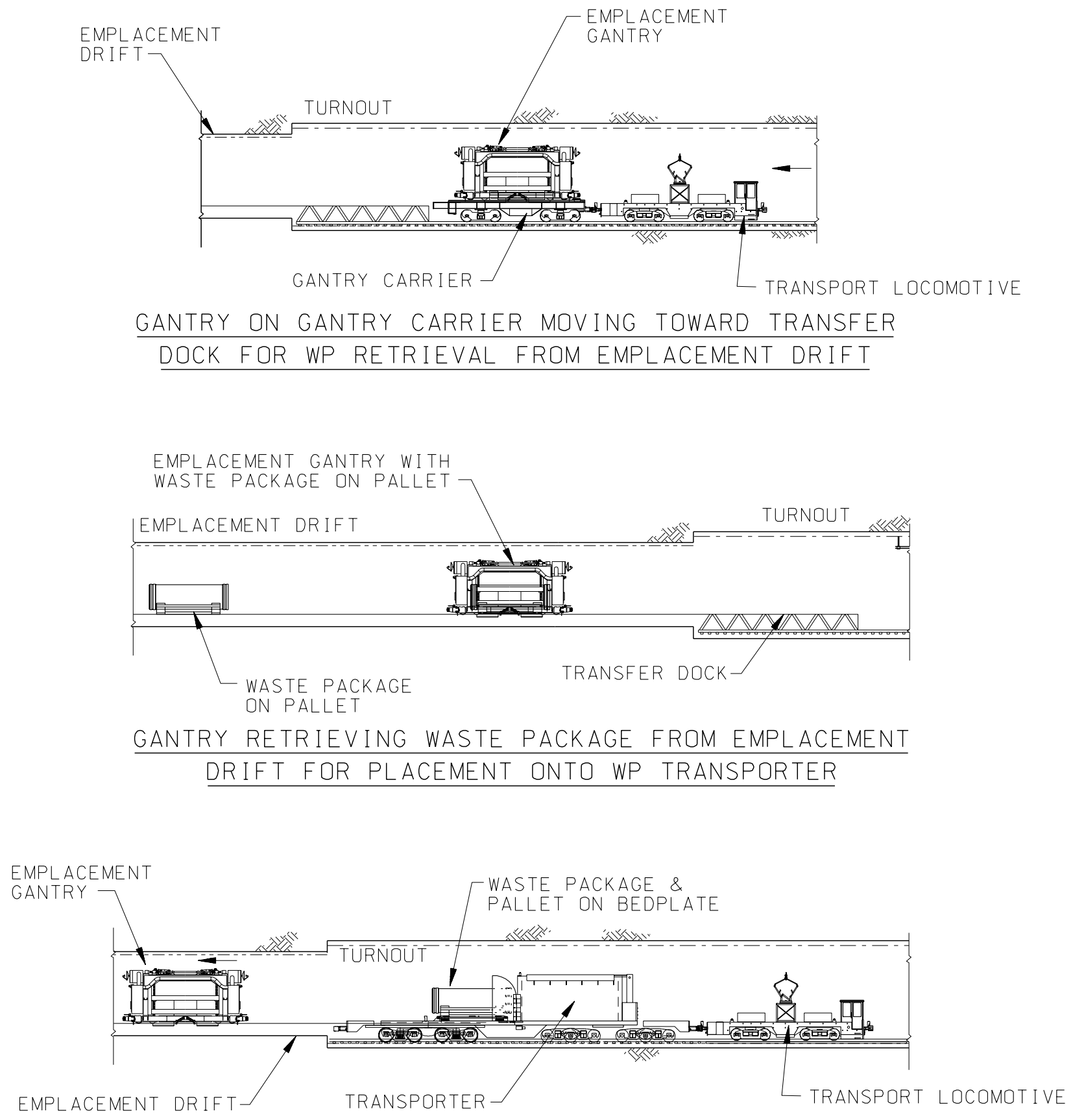

EMPTY GANTRY AFTER WP ON PALLET TRANSFER ONTO BEDPLATE FOR PLACEMENT AND TRANSPORT INSIDE SHIELDED WP TRANSPORTER

Source: adapted from DOE 2002 [DIRS 155943], Figure 2-57.

Figure 6-9. Normal Retrieval Equipment and Sequence 
After the removal of the waste package and emplacement pallet from the waste package transporter, the locomotive and transporter exit the waste package unloading area the same way they arrived, but in the reverse order.

\subsubsection{Removal of the Waste Package Emplacement Gantry from an Emplacement Drift}

After retrieval of all waste packages from an emplacement drift, the waste package emplacement gantry would be relocated for use in another emplacement drift or returned to the surface facilities for maintenance and routine services. The gantry transfer will be by means of the gantry carrier and the transport locomotive, as described in Section 6.2.2.1.2.

\subsubsection{System Interfaces}

The waste retrieval system interfaces with a number of systems to safely accomplish the task of retrieving waste. The waste retrieval system interfaces with the digital control and management information and communication systems for the transmission of data to and from the retrieval equipment and for the remote control of the equipment. The waste retrieval system also interfaces with the subsurface ventilation system for the emplacement drift-operating environment and for travel through the emplacement access doors. The retrieval equipment will travel exclusively on rails and receive electrical power through various means. Interfaces are discussed in the following sections.

\subsubsection{Digital Control and Management Information System Interface}

The digital control and management information system provides supervisory control, monitoring, and remote control of select primary and secondary repository operations. Primary repository operations consist of surface and subsurface activities relating to waste receipt, preparation, and retrieval. Secondary repository operations consist of support operations for waste handling and waste treatment, utilities, and balance-of-plant activities. Remote control of subsurface operations is a direct responsibility of the digital control and management information system (CRWMS M\&O 2000 [DIRS 131505], Section 6.2.2.1). The system provides repository operational information, alarm capability, and response messages during normal and off-normal response situations. The system also has the ability to place equipment, systems, and utilities in a safe operational mode during off-normal response situations. The system also provides data communications, data processing, managerial reports, data storage, and data analysis.

\subsubsection{Subsurface Ventilation System Interface}

The retrieval equipment will require entry and exit from the turnouts and emplacement drifts through the emplacement access doors that are part of the subsurface ventilation system. The interface between the subsurface ventilation system and the retrieval equipment will be supervised by CCC personnel. CCC operators will monitor and control the retrieval equipment so they will be aware that entry into the drift is necessary. The sequence of operations and how the interfaces will work is envisioned as follows:

- The retrieval equipment enters the turnout under the remote control of CCC operators through the digital control and management information system. 
- The subsurface ventilation system will notify the digital control and management information system when the ventilation system is ready for the emplacement access doors to open.

- If conditions are acceptable, the digital control and management information system will direct the subsurface ventilation system that it is permissible for the emplacement access doors to open.

- The subsurface ventilation system will issue commands for the emplacement access doors to open.

- The retrieval equipment, still under remote control of CCC operators through the digital control and management information system, will advance and complete the docking process.

- When retrieval equipment is sufficiently clear of the emplacement access doors, the digital control and management information system will direct the subsurface ventilation system that it is permissible for the emplacement access doors to close.

- The subsurface ventilation system will issue commands for the emplacement access doors to close.

- The retrieval equipment will leave the emplacement transfer dock after operations have been completed.

- The subsurface ventilation system will notify the digital control and management information system when the ventilation system is ready for the emplacement access doors to open.

- If conditions are acceptable, the digital control and management information system will direct the subsurface ventilation system that it is permissible for the emplacement access doors to open.

- The subsurface ventilation system will issue commands for the emplacement access doors to open.

- When retrieval equipment is sufficiently clear of the emplacement access doors, the digital control and management information system will direct the subsurface ventilation system that it is permissible for the emplacement access doors to close.

- The subsurface ventilation system will issue commands for the emplacement access doors to close.

- The subsurface ventilation system will return to normal operation when the doors are detected to be in the closed position. 
As described above, operation of the emplacement access doors will be an integral component of the waste retrieval process that will be coordinated by the digital control and management information system. The only direct interface between the subsurface ventilation system and the waste retrieval system is that the doors are appropriately sized to permit the equipment to pass.

During retrieval operations, the ventilation system will be responsible for controlling the temperature in the emplacement drifts to ensure operability of the equipment involved in the operation.

\subsubsection{Emplacement Transportation System and Power Interfaces}

The retrieval equipment will be rail based and is the same as used for emplacement. Therefore, wherever the equipment must travel, suitable rail must be installed. The layout of the rail must include provisions for the retrieval equipment to be oriented in the proper direction. The layout of the track on the surface will be designed to allow for reversing the direction of travel of the waste retrieval equipment.

Similar to the rail requirements, electrical service must be provided to the retrieval equipment wherever the equipment must operate. This is the same as used for emplacement. To provide power to equipment in the access mains, an overhead catenary wire electrical distribution system will be used. To provide power to the waste package emplacement gantry in the emplacement drifts, a conductor bar or third rail electrical distribution system will be used (CRWMS M\&O 1997 [DIRS 100243], Section 8.2). The transport locomotive will use on-board battery power for operations within the emplacement drift turnouts. The distribution systems will be designed so the required voltage, at sufficient capacity, will be provided to the equipment wherever it is operating within the repository.

The retrieval equipment will use the same rail and electrical power facilities used for emplacement. If alternate surface facilities are constructed, the rail and electrical power facilities will need to be expanded to support the new facilities.

\subsubsection{Transport of Personnel and Maintenance Equipment to the Subsurface Repository}

Maintenance activities need to be periodically performed on the installed equipment located in the subsurface facility. The rail and invert system, electrical distribution system, lighting system, control and monitoring system, and other systems may require adjustment, lubrication, replacement, or calibration over the life of the repository. Transport locomotives coupled to flatbed railcars, personnel carriers, or both will be used to assist maintenance personnel with these activities. Onboard operators will manually drive the locomotive in areas where it is safe to do so.

After appropriate check-in procedures for the maintenance train are completed at the North Portal, locomotive operators will drive down the north ramp of the repository. Status and positional signals will be continuously transmitted to the CCC for remotely monitoring the location of the maintenance crew. Upon completion of activity, the locomotive and maintenance personnel will return to the North Portal where required checkout procedures can be completed. 


\subsection{POTENTIAL RETRIEVAL PROBLEMS}

In general, waste retrieval will be the reverse of waste emplacement operations, and because the subsurface repository will be maintained over the full length of the preclosure period, no major impacts on operational processes are expected. However, should they occur, retrieval problems would be evaluated to identify specific conditions and determine an appropriate strategy for recovery and remedial action. The complexity and duration of the recovery and remedial action for a potential retrieval problem will relate directly to the severity and impact of the specific event or issue occurrence. Engineering studies have considered feasible solutions that might be implemented for potential retrieval events. Some of the potential events or issues that could occur during waste retrieval operations are addressed in the following sections. Although each event or issue will be evaluated in detail, the strategy for recovery from off-normal events includes the following activities:

1. Assessing the immediate status of an involved waste package for personnel safety

2. Notification and reporting to the NRC and other appropriate jurisdictions based on the significance of the event

3. Developing a detailed recovery plan which will include:

a. Assessing nuclear and non-nuclear safety

b. Assessing security impacts during retrieval

c. Assessing impacts of retrieval on the environment at or near the site

d. Establishing access control and isolating the event area from continued operations, if required, to ensure worker safety

e. Confining contamination, if present

f. Collecting technical data

4. Completing actions in accordance with the recovery plan and returning the repository to normal operations

a. Formulating a mitigation plan

b. Designing and providing any additional specialized equipment needed for mitigation

c. Implementing the mitigation plan 


\subsubsection{Repository Conditions}

At the time the decision is made to retrieve waste, one of the first actions will be to assess the condition of the facilities and needs for reconditioning or upgrading facilities and equipment to support retrieval. This effort will include the subsurface facility, mobile equipment, surface facilities, and alternate storage facilities necessary for waste retrieval. The facilities and equipment will be assessed, including a safety hazards analysis, and appropriate measures taken to ensure support for planned retrieval operations.

\subsubsection{Surface Facilities}

The condition of the surface facilities at the time a decision is made to retrieve waste will be determined by a number of factors, including:

- The status of emplacement operations

- The availability of facilities for retrieval operations

- The status of the equipment within the facilities with regard to being serviceable and usable for retrieval operations.

\subsubsection{Mobile Equipment}

An assessment of mobile equipment, similar to that for the surface facilities, will also be needed. Reconditioning and upgrade of mobile equipment will be determined by the results of the assessment. However, less reconditioning and fewer upgrades are expected because the mobile equipment will be in use during the performance confirmation period and during emplacement. Postemplacement activities such as installation of drip shields will also use the mobile equipment.

\subsubsection{Subsurface Facility}

The subsurface facility is designed to facilitate retrieval operations. The design bases, operations, and inspection and maintenance programs work together to maintain access and functionality of the equipment necessary to support retrieval operations. In general, the subsurface facility will be maintained until closure. During the period between the completion of emplacement and closure, several activities that require access and use of the facilities will continue. These activities could include the performance confirmation program, installation of drip shields, and backfilling and sealing openings where applicable. The maintenance programs in place for emplacement will be carried forward for retrieval, and therefore are not repeated here. No adverse subsurface maintenance conditions are expected that would affect retrieval and storage.

During repository operations, selected emplacement drifts will be monitored for environmental conditions and waste package condition as part of the performance confirmation program. Monitoring may be accomplished using instrumentation and remotely operated vehicles with onboard cameras and sensors to detect rockfalls, to do visual inspections, and to do material sampling. These monitoring and inspection activities will provide the necessary information for 
evaluating drift degradation effects, as well as required maintenance and repair of the ground support components that may be needed to provide continued accessibility to the emplacement drifts for possible waste retrieval operations (BSC 2004 [DIRS 172452], Section 3.3).

\subsubsection{Contingency Measures}

In general, no major impacts to operational processes are anticipated. However, a number of operational events have been identified that, while not likely, could affect retrieval. These postulated events and proposed recovery actions, at the conceptual level, are discussed in the following sections. After actions are implemented to recover from these events, it is expected that waste packages will still be retrievable from the repository through the use of a closed and shielded conveyance vehicle, such as the waste package transporter that would protect workers from loose contamination or direct radiation associated with the waste package.

These events are the same that might be encountered during normal emplacement operations, so experience gained will be applied in implementing recovery actions. Each event occurrence will be assessed to identify specific event conditions and to determine an appropriate approach for recovery and remediation. Analyses of events that are potentially adverse to retrieval will continue through operations until permanent closure.

\subsubsection{Derailment of Waste Package Transporter}

Derailment of the loaded or unloaded waste package transporter (or the transport locomotive) may happen on the tracks at the surface, between the surface facilities and the North Portal, or within the subsurface repository during the transport of a waste package. The tracks to the subsurface repository begin at the North Portal, lead through the north ramp, the access mains, and end at the emplacement transfer docks.

Derailment of the waste package transporter (or the transport locomotive) and the mitigation concept for this scenario have been evaluated in Strategies for Recovery from Off-Normal Emplacement and Retrieval Events (BSC 2004 [DIRS 171541]). Additional SSCs may be required to remediate this scenario. A re-railer, commonly used in the rail industry, could be deployed to allow a transport locomotive to pull the waste package transporter wheels back onto the tracks (BSC 2004 [DIRS 171541], Section 5.2.3.1). While operations would need to be conducted remotely, the radiological hazards at this stage are considered manageable. Under the current design, this scenario is considered recoverable and no new safety significant events are anticipated (BSC 2004 [DIRS 171541], Section 6.1.1).

\subsubsection{Waste Package is Immobilized on Transporter Bedplate}

A waste package and emplacement pallet loaded on the roller-supported bedplate of the waste package transporter could only roll partway out of the shielded enclosure of the transporter due to a bedplate malfunction. The bedplate, still attached to the transporter rigid chains, would be immobilized and, by normal operations, could not be pulled back into the shielded enclosure of the transporter or fully extended onto the transfer deck area. This condition could be due to a malfunction of the bedplate roller mechanism or a malfunction of the transporter rigid chain drive mechanism. 
An immobilized waste package and emplacement pallet on the waste package transporter and the mitigation concept for this scenario also have been evaluated (BSC 2004 [DIRS 171541]). No additional SSCs are required to remediate this scenario. Conceptually, a remediation strategy would involve disconnecting the rigid chains from the drive system and using the waste package emplacement gantry to reposition the bedplate to an accessible area of the transfer deck area. From this point, the waste package emplacement gantry can remove the waste package and emplacement pallet by normal means (BSC 2004 [DIRS 171541], Section 5.2.3.2). While operations would need to be conducted in a radiation environment, the radiological hazards at this stage are considered manageable. Under the current design, this scenario is considered recoverable and no new safety significant events are anticipated (BSC 2004 [DIRS 171541], Section 6.1.2).

\subsubsection{Emplacement Access Doors are Damaged}

The emplacement access doors could be damaged by abnormal events such as an impact between the doors and the surrounding infrastructure or by an impact with mobile equipment during waste retrieval operations. Consequently, the doors may not open or close properly.

Damage to the emplacement access doors and the mitigation concept for this scenario have been evaluated (BSC 2004 [DIRS 171541]). No additional SSCs are required to remediate this scenario. With the use of temporary shielding, manual maintenance can be performed on the emplacement access doors (BSC 2004 [DIRS 171541], Section 5.2.3.3). While operations would need to be conducted in a radiation environment, the radiological hazards at this stage are considered manageable. Under the current design, this scenario is considered recoverable and no new safety significant events are anticipated (BSC 2004 [DIRS 171541], Section 6.1.3).

\subsubsection{Waste Package Emplacement Gantry Cannot Retrieve Waste Package}

A waste package emplacement gantry may not be able to retrieve a waste package from an emplacement drift. One such scenario would be when an emplacement gantry, operating within an emplacement drift, is unable to engage an emplacement pallet for retrieval. Another possible scenario may be that a waste package and emplacement pallet cannot be lowered and released from the gantry lifting hooks. These scenarios could prevent normal retrieval of a waste package and emplacement pallet.

The causes for such a scenario may vary, but could be due to a malfunction of the gantry lift mechanism or a misalignment of a waste package and emplacement pallet within the emplacement drift.

Scenarios where a waste package emplacement gantry is unable to retrieve a waste package from an emplacement drift and the mitigation concepts for these have been evaluated (BSC 2004 [DIRS 171541]). Additional SSCs may be required to remediate these scenarios. For scenarios where the emplacement gantry is unable to engage an emplacement pallet within the emplacement drift, a modified mining locomotive equipped with a winching system could be used to maneuver the waste package and emplacement pallet to a more accessible area. If the gantry is unable to lower a waste package, a scissor-lift device could be remotely placed in the emplacement drift. This device would raise the waste package and emplacement pallet from the 
gantry lift hooks, thus allowing the emplacement gantry to be removed from the emplacement drift and repaired (BSC 2004 [DIRS 171541], Section 5.2.3.4). Operations would be conducted remotely within a radiation environment, therefore, the radiological hazards at this preliminary stage are considered manageable. Under the current design, this scenario is considered recoverable and no new safety significant events are anticipated (BSC 2004 [DIRS 171541], Section 6.1.4).

\subsubsection{Derailment of Waste Package Emplacement Gantry in an Emplacement Drift}

Gantry derailment could occur at any point in the emplacement drift, including deep in the emplacement drift near the exhaust main. In this scenario, as the result of the derailment, the emplacement drift rails under the derailed gantry are postulated to be damaged beyond use and the gantry wheels are inoperable (i.e., the gantry will no longer roll). In addition, the electric third rail near the gantry is damaged, thus eliminating the electric power supply to the emplacement gantry. The use of re-railers would not be a feasible option for the mitigation of this scenario due to the damaged rail, gantry wheels, and electric third rail.

Derailment of a waste package emplacement gantry in an emplacement drift and the mitigation concept for this scenario have been evaluated (BSC 2004 [DIRS 171541]). Additional SSCs may be required to remediate this scenario. Re-railers, along with a modified mining locomotive equipped with a winching system, could be used to position the gantry back onto the gantry rails. Alternatively, an emplacement drift gantry carrier could be used to engage the derailed emplacement gantry and transport it to a more accessible location (BSC 2004 [DIRS 171541], Section 5.2.3.5). Operations would be conducted remotely within a radiation environment, therefore, the radiological hazards at this stage are considered manageable. Under the current design, this scenario is considered recoverable and no new safety significant events are anticipated (BSC 2004 [DIRS 171541], Section 6.1.5).

\subsubsection{Rock-fall or Ground Support Failure}

A portion of the ground support could fail within the emplacement drift causing a blockage within the drift. To make the scenario more severe, it can be postulated that the waste package retrieval has begun, waste packages are present, and a loaded waste package emplacement gantry is in the area of the rockfall and is partially buried. In addition, repository infrastructure components, including the ground support, rail tracks, and the electric third rail are severely damaged and inoperable downstream of the area of the rockfall. Data communications and associated video signals from the waste package emplacement gantry would be lost, putting the operators in a temporary information and control blackout condition.

No significant rockfall events are expected during preclosure operations that will lead to a waste package breach. However, should a rockfall occur, event analyses supported by Strategies for Recovery from Off-Normal Emplacement and Retrieval Events (BSC 2004 [DIRS 171541], Section 5.2.3.6) indicate that fallen material from an emplacement drift rockfall can be safely and effectively removed to allow resumption of operations. The process, using remote controlled equipment, while time consuming, would be technically feasible. 
Blockage within the emplacement drift caused by failure of a portion of the ground support and the mitigation concept for this scenario have been evaluated (BSC 2004 [DIRS 171541]), and additional SSCs may be required to remediate this scenario. A modified mining locomotive, equipped with attachments and tools, could be used to excavate fallen debris from the emplacement drift. When the emplacement gantry or previously emplaced waste package is uncovered, the emplacement drift gantry carrier or the modified mining locomotive, or both, could be used to transport these items to more accessible areas (BSC 2004 [DIRS 171541], Section 5.2.3.6). Operations would be conducted remotely within a radiation environment, therefore, the radiological hazards at this stage are considered manageable. Under the current design, this scenario is considered recoverable and no new safety significant events are anticipated (BSC 2004 [DIRS 171541], Section 6.1.6). 


\section{ALTERNATE STORAGE FACILITY}

\subsection{SCOPE}

If waste is retrieved from the subsurface repository, one of two options is likely to be proposed: the waste will be retrieved and put into long-term surface storage at Yucca Mountain or the waste will be held in short-term storage at Yucca Mountain, pending further processing or transfer to an offsite location. The specific design and operational plan for the disposition of the retrieved waste will depend on the reason for retrieval, the final disposition of the waste, consideration of associated hazards, applicable regulations (to be established in the future), and the licensing process enacted for retrieval.

If the waste is to be put into long-term surface storage at Yucca Mountain, one of the three following scenarios is likely to occur:

- Scenario 1-Retrieval occurs after all waste has been emplaced and the existing surface facilities have been decommissioned. In this scenario, the concept of operations is that the retrieved waste packages must be delivered to a new facility, the Alternate Storage Facility, for processing and storage. This activity would include placing the waste packages into suitable surface storage containers and placing them in an Alternate Storage Facility.

- Scenario 2-Retrieval occurs after all the waste has been emplaced in the subsurface repository, but before the surface facilities are decommissioned. In this case, a redesign and modification of the surface facilities would be undertaken. The scope of the redesign would focus on the concept of operations described in Scenario 1.

- Scenario 3-Retrieval occurs before all of the waste has been received on site and emplaced. It is likely that waste will continue to be shipped to the site. In this case, it is assumed that the existing surface facilities would still be needed. The redesign and modification of the existing surface facilities may be more limited but would still need to satisfy the concept of operations described in Scenario 1.

The reason for retrieval may be such that the capacity of the surface facility would be considerably less than the subsurface waste inventory. For example, if the waste is to be shipped offsite, the size of the surface facility would be limited to that required for short-term storage and preparation for shipment in licensed shipping casks. Those casks may receive the entire waste package or the waste may have to be removed from the waste package and repackaged for offsite transport. A detailed evaluation of the storage area requirements and the storage system configuration would be performed during the comprehensive assessment of an Alternate Storage Facility.

It is premature to consider specific designs for any of these possible scenarios because the reason for retrieval is not known and there are no regulations to provide licensing and design guidance. Therefore, only one concept has been selected to be representative of the above noted scenarios and illustrates the flow of activities that would take place for these alternative scenarios. Scenario 1, the option that the waste is to be placed in long-term surface storage at Yucca Mountain, is selected. This concept illustrates the flow of accepting waste packages at a surface 
facility, unloading them from waste package transporters, reloading them into new containers, and moving them to a storage area. These activities will be similar for the other two scenarios, differing only in details. This should be interpreted as conceptual and does not represent a design that is to be implemented without further evaluation. As is the case for the facility size, handling operations of the Alternate Storage Facility will depend on the amount of waste already received at the site at the time of the decision.

\subsection{CONCEPT OF OPERATIONS}

The specific design and operational plan for the surface facilities depend on specific needs for the storage and hazards encountered in the retrieval process. Modifications to facilities existing at the site may be appropriate or new facilitates may be needed. In-depth planning will be initiated to assess these needs should retrieval be necessary. The storage concepts considered here are based on documented assumptions, engineering studies, and regulatory requirements. Studies on storage facility concepts are presented in Repository Surface Design Engineering Files Report (CRWMS M\&O 1999 [DIRS 104508], Attachment I).

A comprehensive repository assessment, operational analysis, and detailed design for the Alternate Storage Facility will be performed should the decision to retrieve be made. This effort will include ALARA and criticality considerations and may lead to other concepts of operations. For example, a horizontal waste package handling and storage system may be preferred, but other orientations will be considered. The nature of the waste package handling system and the size and configuration for the storage area will be evaluated in the comprehensive assessment.

During retrieval, it is assumed that waste packages are removed from the emplacement drifts, moved to the surface, and transported to the Alternate Storage Facility, which stores the retrieved waste in a manner that protects the health and safety of the public and workers, and maintains the quality of the environment. The Alternate Storage Facility consists of a Waste Retrieval Transfer Building, support facilities, and a number of reinforced concrete storage pads located near the North Portal. The facility is equipped for unloading waste packages from the waste package transporter, transferring waste packages to vertical concrete storage units (CSUs), and transporting the CSUs to a dry concrete storage pad.

\subsection{SITE LOCATION AND DESCRIPTION}

A possible site for the Alternate Storage Facility (Figure 7-1) is in Midway Valley near the repository North Portal (CRWMS M\&O 1999 [DIRS 104508], Attachment I, Section 3). The locations identified for onsite aging facilities that can accommodate up to 40,000 MTHM are also illustrated in Figure 7-1. This capacity includes 19,000 MTHM in contingency aging at an area located directly north of the site facilities. The aging areas could be used for alternate storage, if necessary. The proposed alternate waste retrieval storage facility would be located in Midway Valley adjacent to the 20,000 MTHM aging area that is northwest of the site facilities (Figure 7-1). This new area of approximately 240 acres overlays the future contingency expansion location of the additional 19,000 MTHM aging area and is sufficient to store up to 70,000 MTHM, if needed. Use of this area for retrieval storage would require appropriate characterization, siting studies, and site preparation activities. 


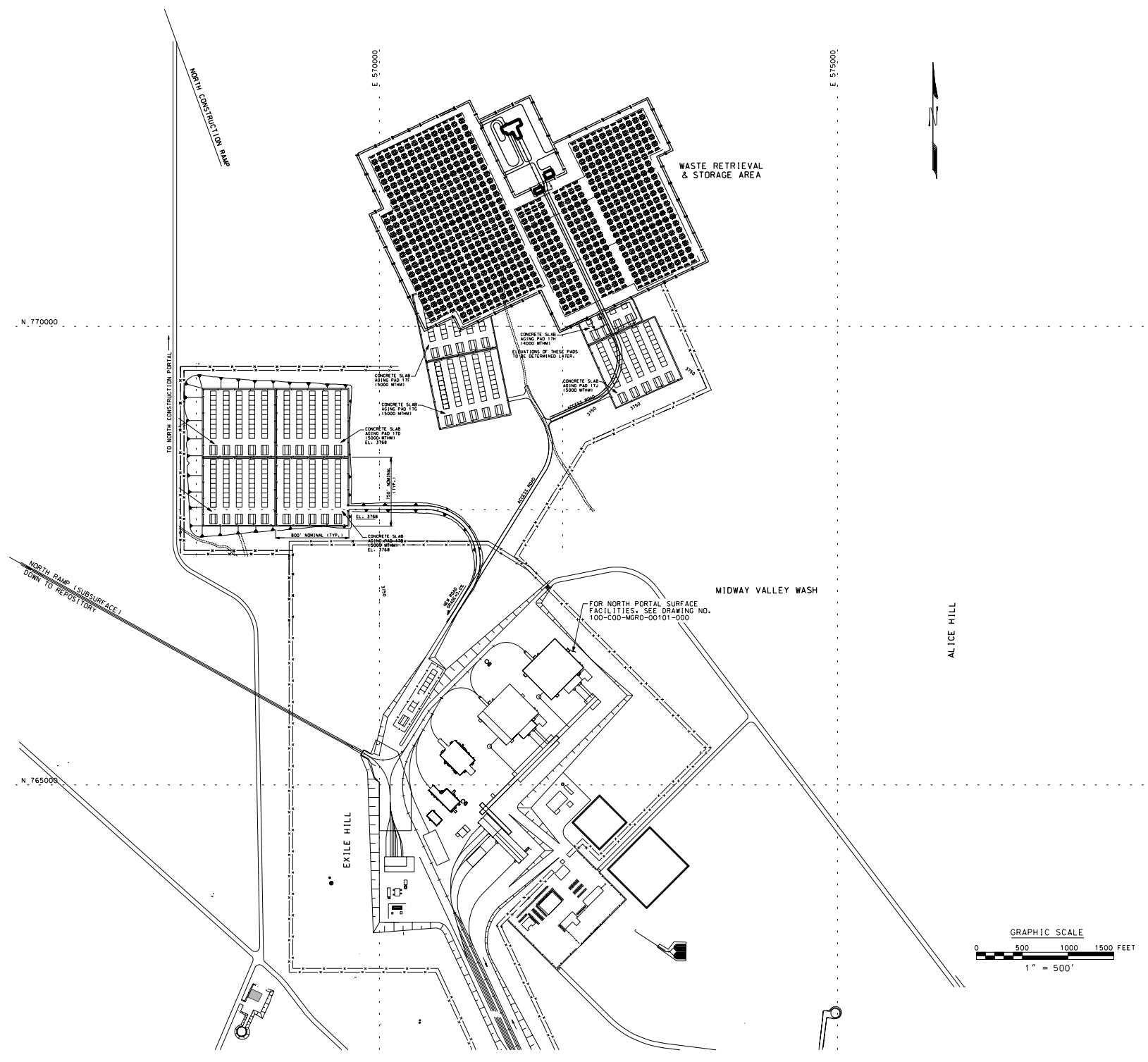

Source: adapted from CRWMS M\&O 1999 [DIRS 104508], Figure I-1; BSC 2004 [DIRS 172171].

NOTE: This figure illustrates the overlay of the potential Alternate Storage Facility over a portion of the currently proposed waste aging areas.

Figure 7-1. Possible Alternate Storage Facility, Scenario 1 Conceptual Design 
Location selection criteria to be considered for the Alternate Storage Facility include:

- Proximity to the repository North Portal

- Retrievability of repository waste in the allocated timeframe

- Space for dry storage of retrieved waste

- Locating the waste at one location as opposed to storing it at several smaller locations

- Identification of optimal environmental conditions

\subsection{FACILITIES}

\subsubsection{Alternate Storage Facility}

The anticipated flow of operations, based on Scenario 1, is illustrated in Figure 7-2. A conceptual layout of the proposed Alternate Storage Facility is illustrated in Figure 7-3. The waste storage area is configured for modular storage pads. Each modular concrete storage pad provides space for transport and storage of CSUs. Positions are provided on each side of the transport aisle used for moving the CSU into position. The selection of concrete storage units is only for illustrative purposes and does not reflect a commitment to this design concept.

The Alternate Storage Facility (Figure 7-3) contains space for a Waste Retrieval Transfer Building, a waste package transporter queuing yard, a CSU staging area, the modular CSU storage area, site support facilities, an inspection gatehouse, and administrative and security facilities.

The Alternate Storage Facility site is furnished with rail and road access. A new rail line would be constructed from the existing repository main gate to the Alternate Storage Facility.

The Alternate Storage Facility, including the concrete storage pad areas, is enclosed with a double security fence. One buffer is provided between the CSUs and the double security fence and a second buffer is provided between the double security fence and the site boundary, located a substantial distance from the Alternate Storage Facility.

\subsubsection{Waste Retrieval Transfer Building}

A conceptual design of the Waste Retrieval Transfer Building is illustrated in Figure 7-4. Empty CSUs are delivered by rail to the site, unloaded in the CSU staging area, transported to the Waste Retrieval Transfer Building, and staged in the CSU loading bay. The upper and lower sections of the cask, cask loading plates, and cask shield lids are transferred into the shielded portion of the building for waste package loading. 

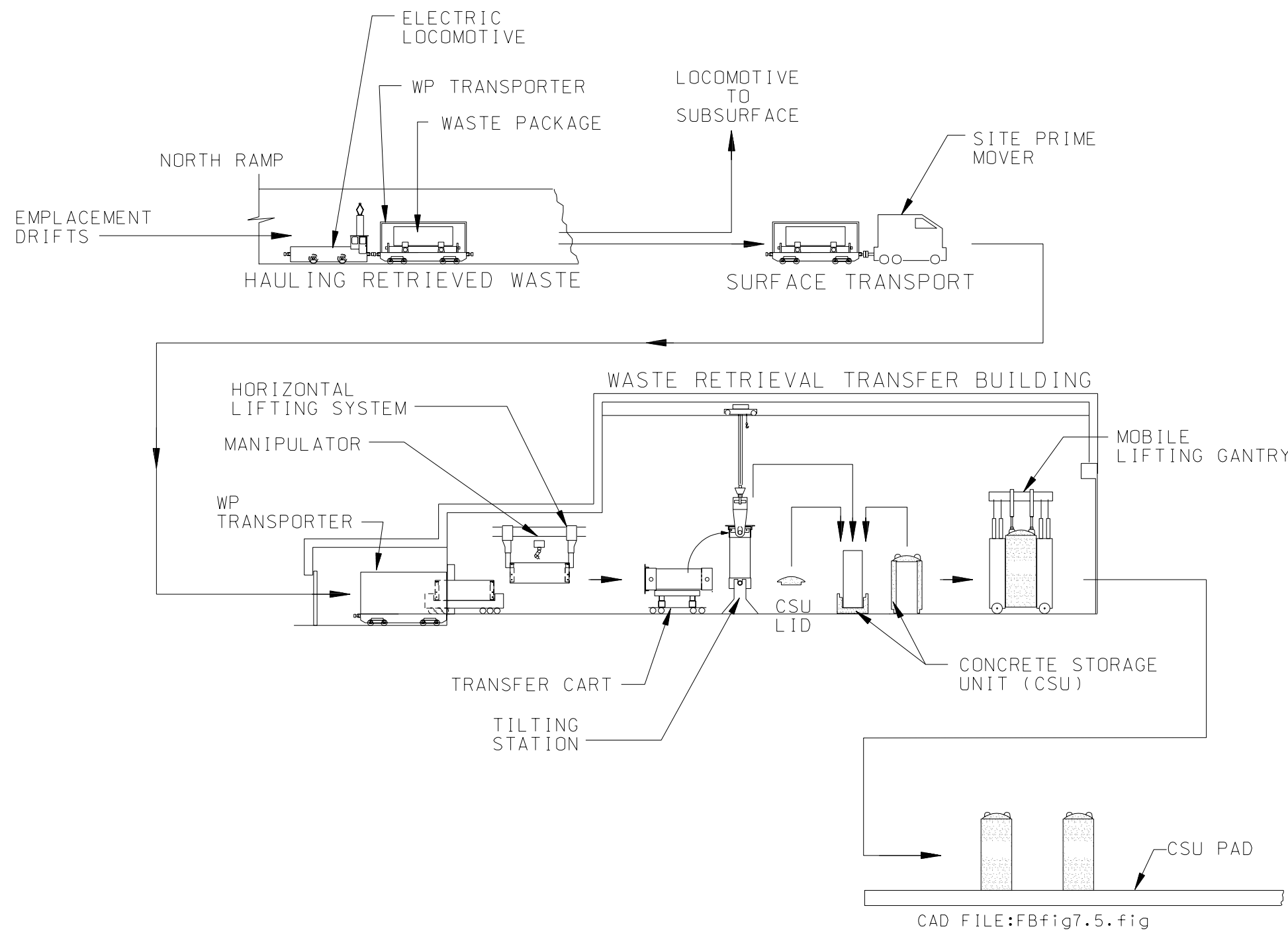

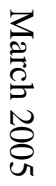

Source: adapted from CRWMS M\&O 1999 [DIRS 104508], Figure I-5.

Figure 7-2. Conceptual Operations Mechanical Flow, Scenario 1 Conceptual Design 


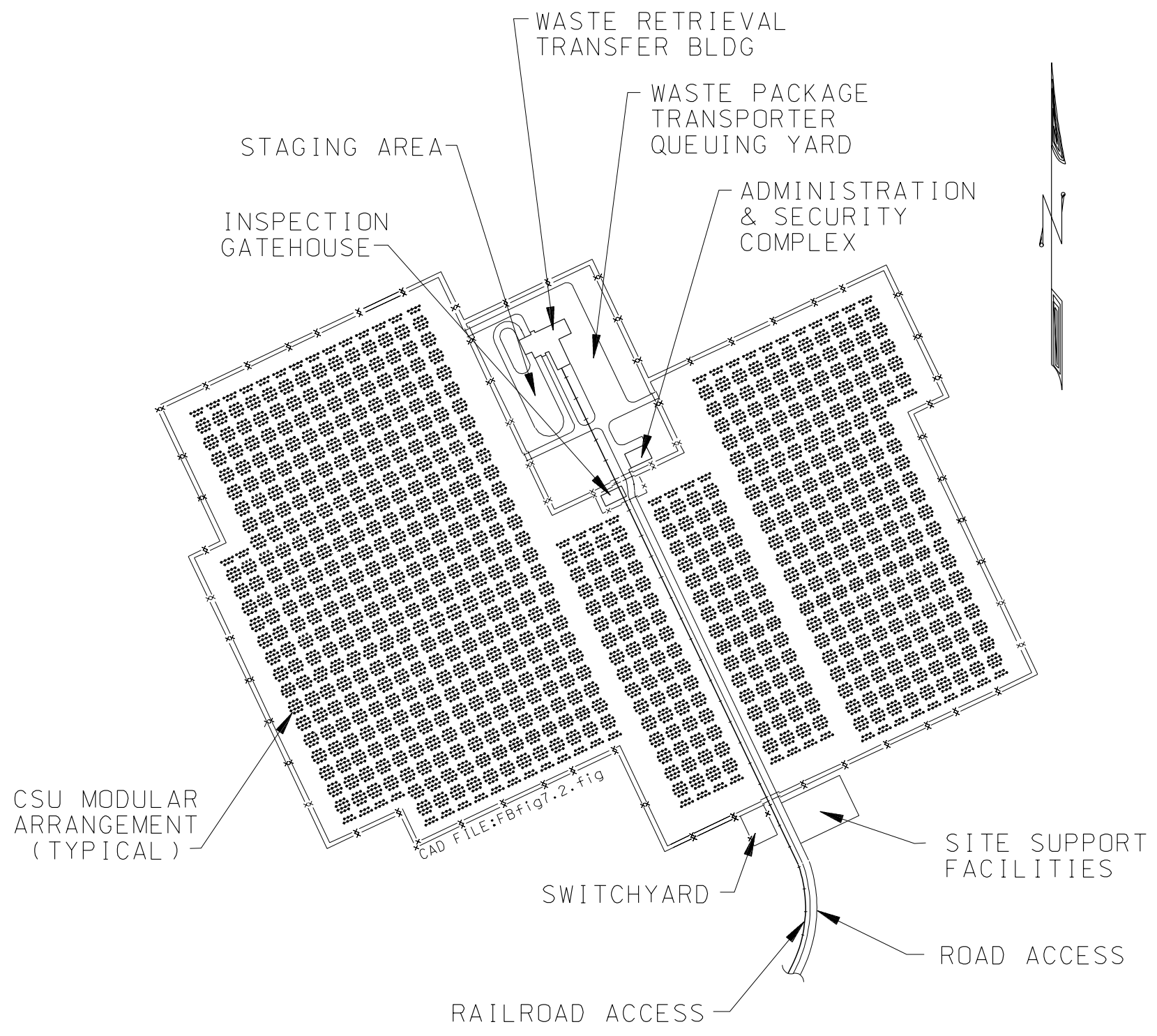

Source: CRWMS M\&O 1999 [DIRS 104508], Figure I-2.

Figure 7-3. Alternate Storage Facility Layout, Scenario 1 Conceptual Design 


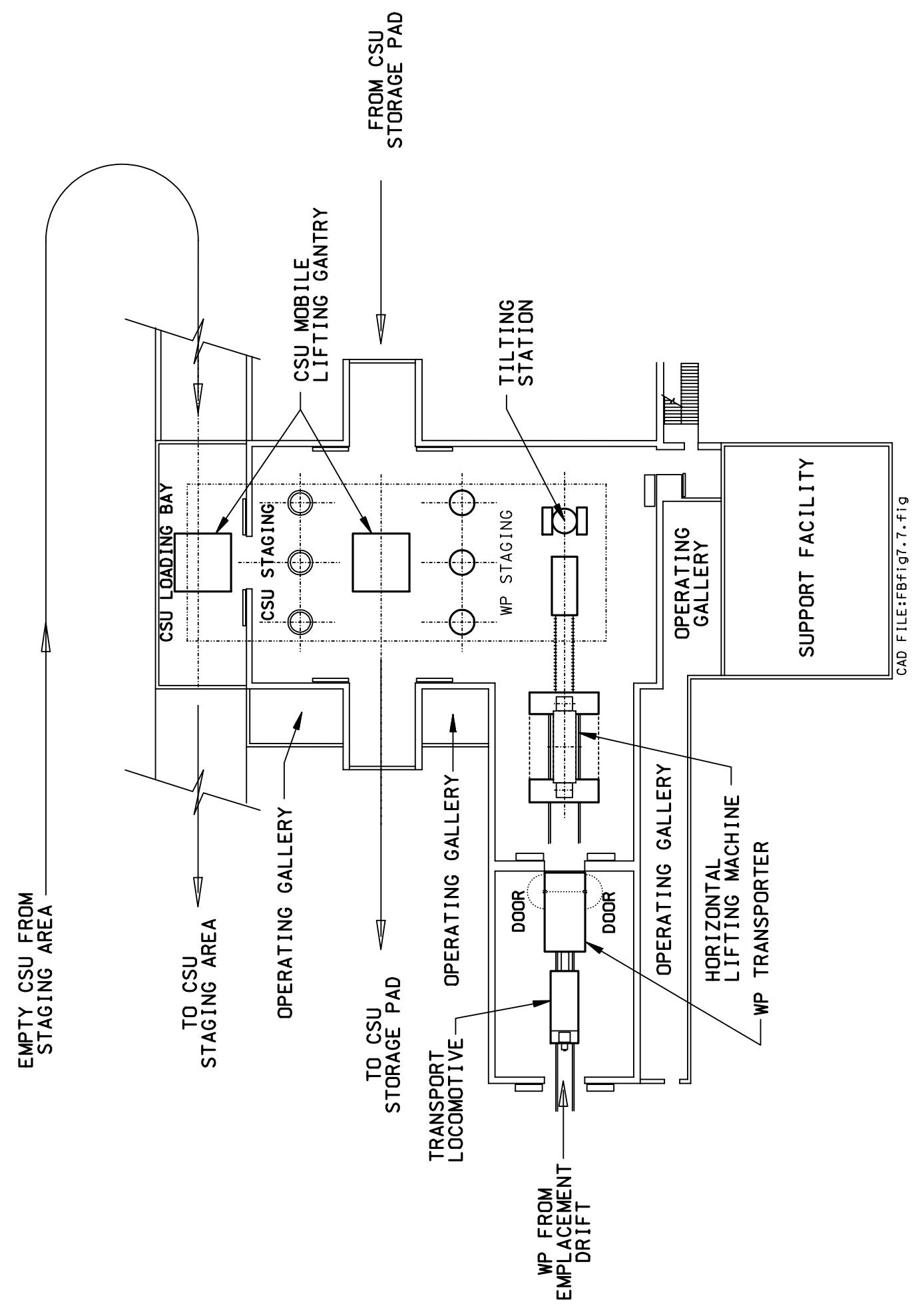

Source: CRWMS M\&O 1999 [DIRS 104508], Figure I-6.

Figure 7-4. Waste Retrieval Transfer Building, Scenario 1 Conceptual Design 
Waste package transporters are received at the Alternate Storage Facility, staged in the waste package transporter queuing yard, and moved into the Waste Retrieval Transfer Building using the waste transporter locomotive (a site prime mover could be used). The waste package transporter is positioned at the waste package transfer dock and secured for waste package transfer. The waste package and emplacement pallet are remotely transferred from the transporter to a waste package transfer cart and lifting fixtures (to be determined) are installed. The transfer cart moves the waste package to a tilting station, where the waste package is rotated to a vertical orientation. The waste package is then transferred directly to the base or lower portion of the CSU (Figure 7-5) or to one of three available waste package staging areas. When the CSU shield or upper portion of the CSU is installed over the waste package, the CSU lid, cover, and locking plates are remotely installed. The CSU is then ready for transport to a concrete storage pad.

A CSU mobile lifting gantry is used to transport the loaded CSU to its storage pad. The conceptual design of the mobile lifting gantry is illustrated in Figure 7-6. The remotely operated mobile lifting gantry straddles the CSU, engages the CSU lifting bails, lifts the CSU and waste package, transports the loaded CSU to a designated storage pad, positions the CSU on the pad (Figure 7-7), and lowers the CSU onto the pad.

The Waste Retrieval Transfer Building has two wings, one for waste package receipt and transfer, and one for CSU loading and handling. The two wings are perpendicular to each other. The Waste Retrieval Transfer Building also includes a CSU loading bay for staging and transfer of unloaded CSUs and an adjacent support facility.

\subsubsection{Concrete Storage Unit}

The CSU concept is illustrated in Figure 7-5. The CSU consists of an annular vertical cylinder and base. The inside diameter provides a gap between the CSU and the waste package for natural circulation cooling of the waste package. Based on the design of the CSU, multiple sizes may be needed to accommodate the various sizes of waste package. The CSU includes concrete shielding for radiation protection to reduce gamma and neutron doses. When the CSU is assembled and loaded with a waste package, a shielded lid and cover are installed. 


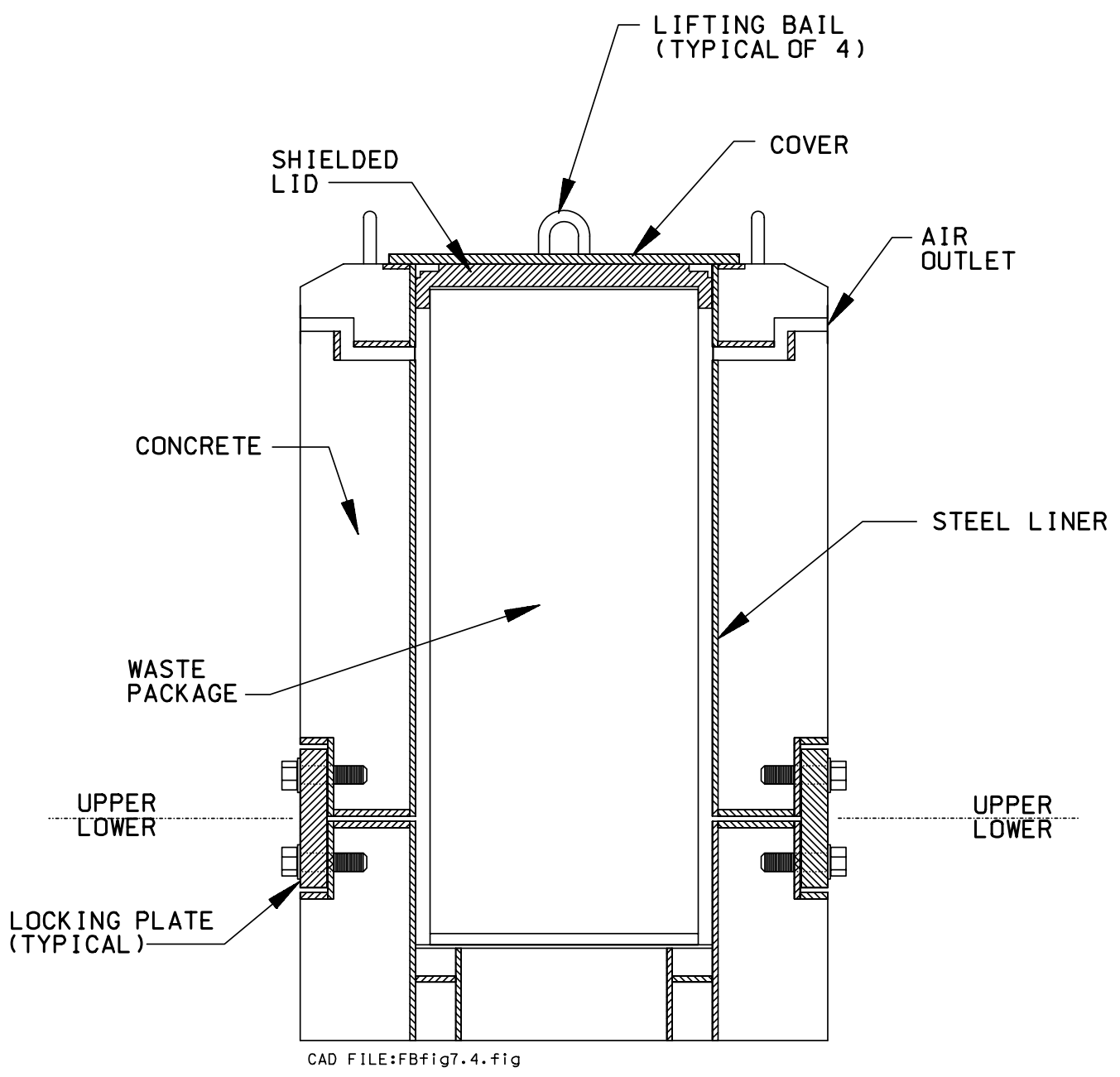

Source: CRWMS M\&O 1999 [DIRS 104508], Figure I-4.

Figure 7-5. Concrete Storage Unit, Scenario 1 Conceptual Design 


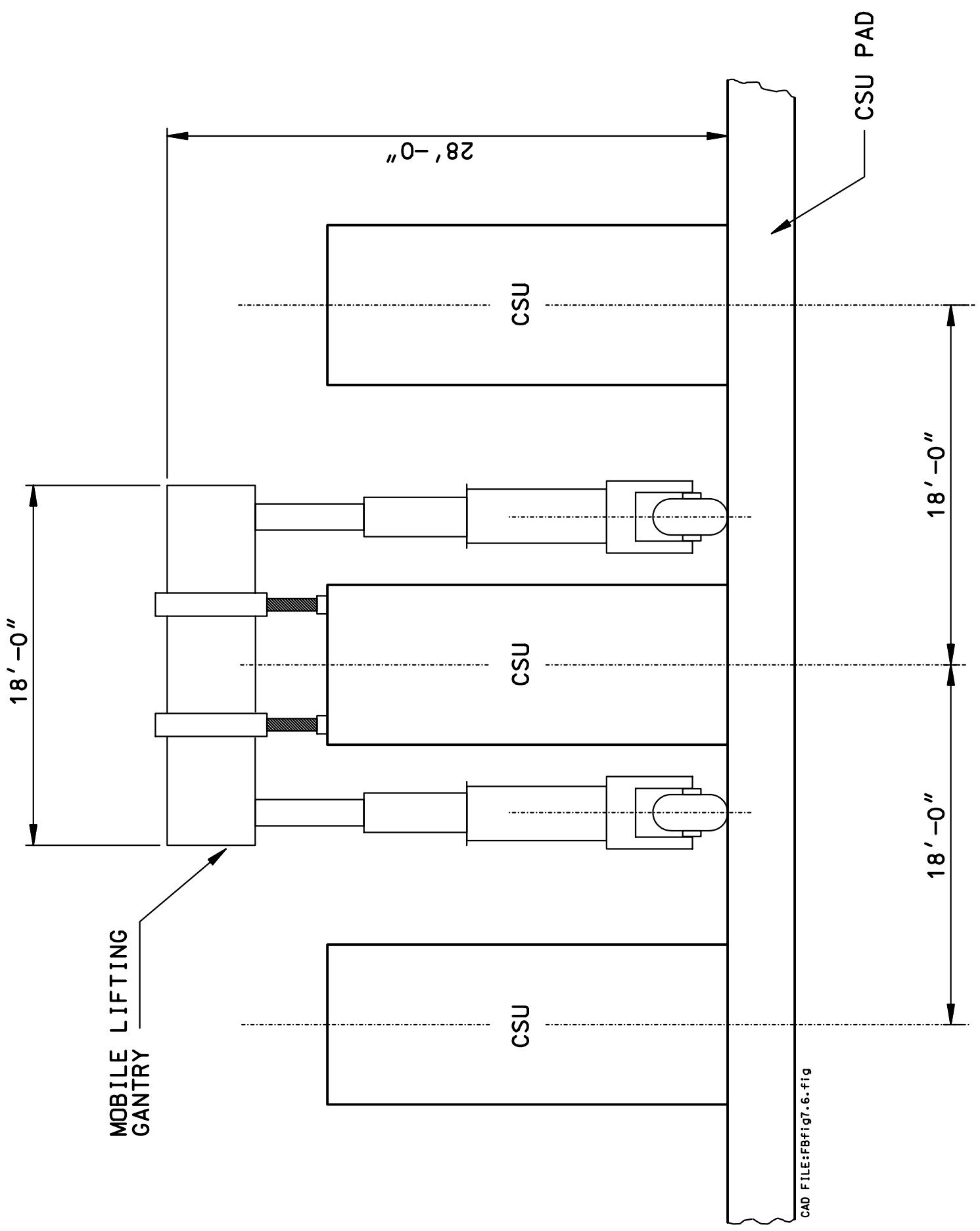

Source: CRWMS M\&O 1999 [DIRS 104508], Figure I-7.

Figure 7-6. Mobile Lifting Gantry, Scenario 1 Conceptual Design 


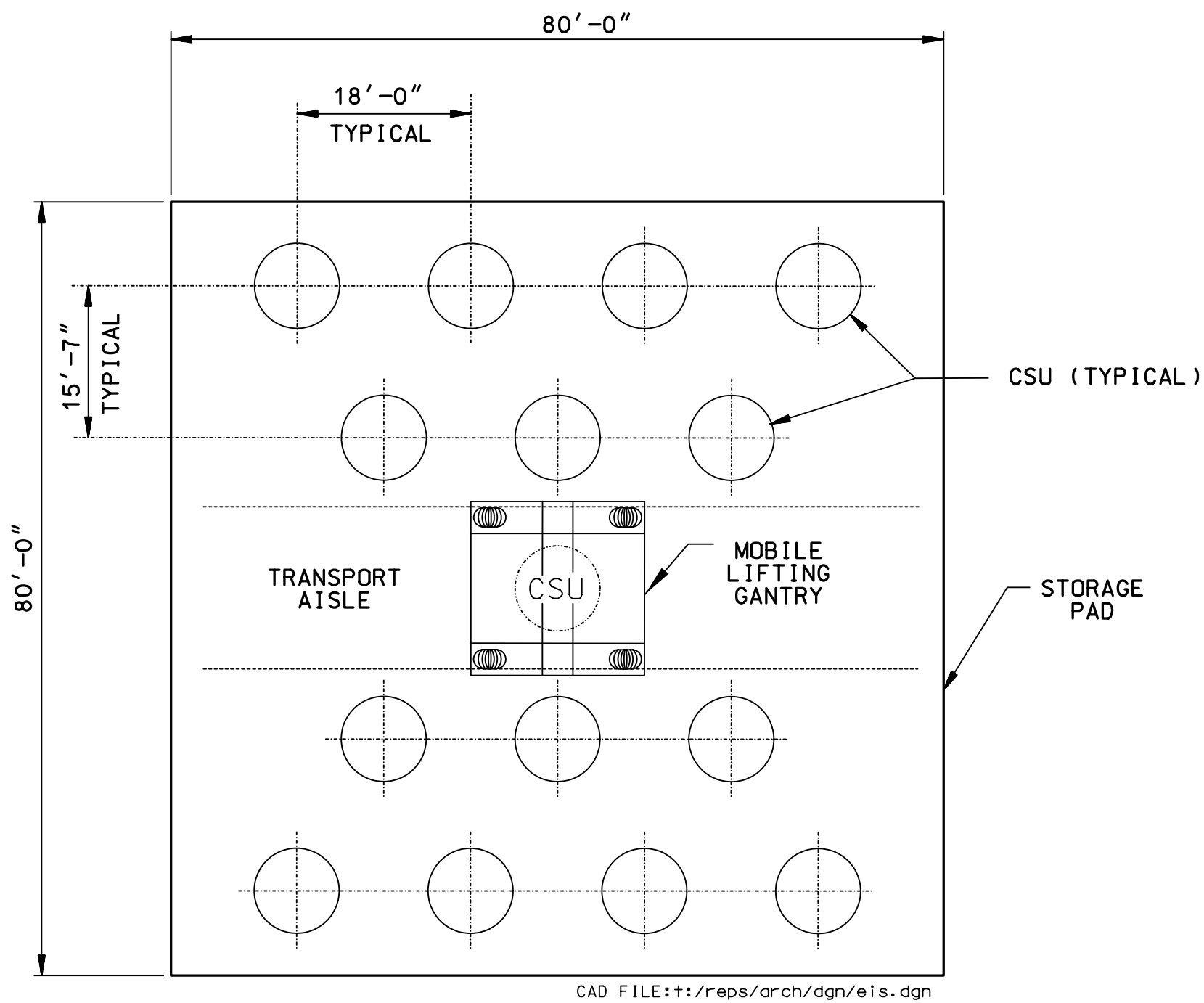

Source: CRWMS M\&O 1999 [DIRS 104508], Figure I-3.

Figure 7-7. Modular Concrete Storage Pad, Scenario 1 Conceptual Design 


\section{INTENTIONALLY LEFT BLANK}




\section{RADIATION PROTECTION}

\subsection{RETRIEVAL OPERATION-HAZARDS ANALYSES AND PRECLOSURE SAFETY}

Events associated with the subsurface transport and emplacement of waste packages are described in Categorization of Event Sequences for License Application (BSC 2005 [DIRS 171429], Section 6.3.6.1). While retrieval was beyond the scope of that document, these events are assumed to be applicable for retrieval because of the assumption that retrieval is largely the reverse of emplacement (Assumptions, Section 3). Should retrieval be required, additional dose calculations for Category 1 and Category 2 event sequences associated with retrieval will be developed prior to initiating retrieval operations to ensure that any potential event sequences are considered.

\subsection{ALTERNATE STORAGE FACILITY OPERATIONS-HAZARDS ANALYSES AND PRECLOSURE SAFETY ASSESSMENTS}

An operations hazard analysis and a preclosure safety assessment have not been made for the Alternate Storage Facility because of the conceptual nature of the design. These activities will be conducted during the design stage, should the retrieval decision be made.

\subsection{OPERATION-OCCUPATIONAL DOSE ESTIMATES AND ENGINEERING AND ADMINISTRATIVE CONTROLS (ALARA IMPLEMENTATION)}

Occupational dose estimates have not been made specifically for retrieval. However, the radiation exposure considerations applicable for emplacement operation will also apply for retrieval, along with any additional considerations based on pre-retrieval radiological survey activities.

The design of the surface facilities is intended to reduce or eliminate waste package radioactive contamination during emplacement. Surveying waste packages before emplacement will control contamination on the surface of the waste packages. A surface contamination limit has been established based on dose consequences of radionuclide releases from the repository exhausts (Edwards and Yuan 2003 [DIRS 164177]). If the waste package surface contamination level exceeds the recommended level, it will be decontaminated and sent to the subsurface only after ensuring that the contamination is within the established limit. Activation products generated in the air and host rock surrounding waste packages due to neutron exposure are another source of radiation that may contribute dose through ingestion and submersion. Neutron activation of host rock and silica dust has been evaluated and found to be significantly less than the 10 CFR Part 20 limits for airborne releases (BSC 2003 [DIRS 164562]). The potential for activated dust to affect the surface contamination levels of a waste package will also be considered. The ventilation system is designed to minimize the spread of contamination into occupied areas. The retrieval of waste packages from the drifts will be done using remote technology to eliminate the presence of occupational workers in high radiation areas. Further administrative controls, such as surveying and monitoring, will be used in conjunction with engineering controls to reduce individual and collective dose to occupational workers during retrieval operation. The regulatory requirements for conducting surveys and monitoring contamination levels and radiation doses will be followed. 
A combination of engineering features, management controls, radiation safety considerations, and regulatory requirements and guidance will be employed in the design and operation of waste retrieval to implement ALARA dose principles. 


\section{COMPATIBILITY OF RETRIEVAL WITH RELATED REPOSITORY OPERATIONS}

\subsection{PERFORMANCE CONFIRMATION}

The scope of the performance confirmation program is to include monitoring for retrieval as stated by the NRC (66 FR 55732 [DIRS 156671], Section III, Section 2.3, page 55744) on performance confirmation:

it is important that the general requirements also include consideration of operational aspects of repository performance, for example, the ability to retrieve waste as required at 10 CFR 63.111(e) [DIRS 156605]. An organized program of collecting subsurface information during repository construction and operation that confirms the design assumptions regarding the ability to retrieve waste is therefore an important performance confirmation activity.

As stated in 10 CFR 63.111(e)(1) [DIRS 156605]:

The geologic repository operations area must be designed to preserve the option of waste retrieval throughout the period during which wastes are being emplaced and thereafter, until the completion of a performance confirmation program and Commission review of the information obtained from such a program...

The relationship between retrieval and the performance confirmation program is discussed in the Performance Confirmation Plan (BSC 2004 [DIRS 172452]). Performance confirmation activities will be performed to ensure that the option to retrieve waste remains viable.

\subsection{DRIP SHIELD REMOVAL}

Limited design analysis (CRWMS M\&O 2000 [DIRS 147702]) has shown that, on a conceptual level, drip shield placement is feasible with current technology and equipment. It is possible that retrieval could be ordered after drip shields have been installed. Should this be the case, the same equipment that placed the drip shields could remove them in advance of waste package retrieval (Assumptions, Section 3). The duration of the retrieval period may be affected because drip shield removal would require additional time. Retrieval analyses conducted in preparation for waste retrieval would assess actions based on whether drip shields had been previously installed and the impacts, if any, that would be imposed on the retrieval schedule (Section 4). 


\subsection{BACKFILLING OF EMPLACEMENT DRIFTS}

Currently the Yucca Mountain Project baseline does not include backfilling of the emplacement drifts, although this option cannot be precluded. Accordingly, the current approach for retrieval does not consider the need to remove backfill. Based on previous studies of events, such as drift collapse (Section 6.3.2.6), removal of backfill would require a comprehensive evaluation of safety and operating conditions and a detailed implementation plan that included identification of appropriate equipment. If the decision to backfill the emplacement drifts is made, it is possible that retrieval could be ordered after placement of the backfill has been initiated. The proposed schedule for retrieval (Section 4) does not include time for backfill removal. It is assumed (Section 3) that removal can take place without affecting the retrieval schedule. 


\section{SUMMARY}

The Code of Federal Regulations (10 CFR 63.111(e)(1) [DIRS 156605]) requires the repository design to preserve the option of waste retrieval throughout the period during which wastes are being emplaced and thereafter until the completion of a performance confirmation program. Currently the design includes a 50-year period of forced ventilation following the completion of waste emplacement (BSC 2004 [DIRS 171541]). Consequently, because the performance confirmation program will run through the period of forced ventilation, the retrieval option must be preserved until completion of the ventilation program. The current repository schedule shows a waste emplacement period of 24 years. On this basis, the waste retrieval option must be preserved for an additional 50 years to the completion of the ventilation program.

Regulation 10 CFR 63.111(e)(3) [DIRS 156605] states that a reasonable schedule for retrieval is one that would permit retrieval in about the same amount of time as that required for constructing the geologic repository operations area and emplacing waste. The current repository schedule shows a 2-year construction period followed by a waste package emplacement period of 24 years. On this basis, retrieval should require 26 years, or approximately 30 years for planning purposes.

An assumption used in this report is that waste retrieval can be accomplished by reversing the emplacement process. The waste package emplacement gantry will remove a waste package from an emplacement drift, move to the emplacement transfer dock, load the waste package onto the waste package transporter, and return to retrieve another waste package. The waste package transporter will return the waste package to the surface

The reasons for waste retrieval would dictate specific surface facility designs and activities. The Alternate Storage Facility would accept waste packages from the subsurface, repack them in a concrete storage cask, and house the retrieved waste packages until a final disposition is made. Regulatory actions would be required for final disposition of the waste.

An initial retrieval decision would include the preparation of retrieval plans. The retrieval plan development process would include the following steps:

- Evaluate hazards associated with retrieval; evaluate facilities and equipment available for use in retrieval operations; evaluate licensing requirements for retrieval applicable at the time of retrieval.

- Develop a license amendment request to include a design with supporting safety analysis and technical specifications to implement an operational retrieval plan.

- NRC review, attendant with any other regulatory actions

- Assuming approval of the amendment, needed facilities would be constructed, procedures would be developed governing the retrieval process, and retrieval would be commenced. 
The concepts presented in this report are not to be used as the basis for design, construction, or procurement.

If a decision is made to retrieve, revised regulations may be in place or may be needed to address retrieval and storage. The design of systems, equipment, and processes would comply with these regulations. As 10 CFR Part 63 [DIRS 156605] does not provide guidance for the retrieval and storage of radioactive waste, concepts discussed in this report are consistent with preserving public safety and waste isolation.

A conceptual evaluation of potential off-normal subsurface events indicates that while an offnormal event may temporarily interrupt retrieval operations, no postulated off-normal event would ultimately prevent a successful retrieval operation. 


\section{REFERENCES}

\subsection{DOCUMENTS CITED}

100243 CRWMS M\&O (Civilian Radioactive Waste Management System Management \& Operating Contractor) 1997. Repository Rail Electrification Analysis. BCAC0000001717-0200-00002 REV 00. Las Vegas, Nevada: CRWMS M\&O.

ACC: MOL.19980122.0462.

104508 CRWMS M\&O (Civilian Radioactive Waste Management System Management \& Operating Contractor) 1999. Repository Surface Design Engineering Files Report. BCB000000-01717-5705-00009 REV 03. Las Vegas, Nevada: CRWMS M\&O. ACC: MOL.19990615.0238.

131505 CRWMS M\&O (Civilian Radioactive Waste Management System Management \& Operating Contractor) 2000. Subsurface Repository Integrated Control System Design. ANL-MGR-CS-000001 REV 00. Las Vegas, Nevada: CRWMS M\&O. ACC: MOL.20000321.0284.

147702 CRWMS M\&O (Civilian Radioactive Waste Management System Management \& Operating Contractor) 2000. Drip Shield Emplacement Gantry Concept. ANL-XCSME-000002 REV 00. Las Vegas, Nevada: CRWMS M\&O.

ACC: MOL.20000418.0817.

154553 BSC (Bechtel SAIC Company) 2001. Gantry Structural/Control System Analysis. ANL-WER-MD-000001 REV 00. Las Vegas, Nevada: Bechtel SAIC Company. ACC: MOL.20010425.0003.

155732 BSC (Bechtel SAIC Company) 2001. Concept of Operations for Waste Transport, Emplacement, and Retrieval. TDR-WER-ME-000001 REV 00. Las Vegas, Nevada: Bechtel SAIC Company. ACC: MOL.20010713.0046.

155943 DOE (U.S. Department of Energy) 2002. Yucca Mountain Science and Engineering Report. DOE/RW-0539, Rev. 1. Washington, D.C.: U.S. Department of Energy, Office of Civilian Radioactive Waste Management. ACC: MOL.20020404.0042.

164177 Edwards, T.A. and Yuan, Y. 2003. Recommended Surface Contamination Levels for Waste Packages Prior to Placement in the Repository. 000-30R-OSS0-00100-000000. Las Vegas, Nevada: Bechtel SAIC Company. ACC: ENG.20030903.0001.

164562 BSC (Bechtel SAIC Company) 2003. Radiological Releases Due to Air and Silica Dust Activation in Emplacement Drifts. 800-00C-EBS0-00100-000-00A. Las Vegas, Nevada: Bechtel SAIC Company. ACC: ENG.20030509.0001.

165572 BSC (Bechtel SAIC Company) 2003. Underground Layout Configuration. 800P0C-MGR0-00100-000-00E. Las Vegas, Nevada: Bechtel SAIC Company. ACC: ENG.20031002.0007. 
166503 Williams, N.H. 2003. “Contract No. DE-AC28-01RW12101 - Licensing Position034, Preclosure Period Duration.” Letter from N.H. Williams (BSC) to J.D. Ziegler (DOE/ORD), December 15, 2003, 1209039726, with enclosure.

ACC: MOL.20040107.0059.

167425 BSC (Bechtel SAIC Company) 2004. Emplacement Gantry Design Calculation. 800-MQC-HEE0-00200-000-00B. Las Vegas, Nevada: Bechtel SAIC Company. ACC: ENG.20040303.0034.

167428 BSC (Bechtel SAIC Company) 2004. Waste Package Transporter Design Calculation. 800-MQC-HET0-00100-000-00B. Las Vegas, Nevada: Bechtel SAIC Company. ACC: ENG.20040227.0003.

169002 BSC (Bechtel SAIC Company) 2004. Emplacement \& Retrieval General Arrangement Emplacement Gantry. 800-MQ0-HEE0-00101-000-00B. Las Vegas, Nevada: Bechtel SAIC Company. ACC: ENG.20040303.0045.

171190 BSC (Bechtel SAIC Company) 2005. Q-List. 000-30R-MGR0-00500-000-001. Las Vegas, Nevada: Bechtel SAIC Company. ACC: ENG.20050217.0010.

171429 BSC (Bechtel SAIC Company) 2005. Categorization of Event Sequences for License Application. 000-00C-MGR0-00800-000-00B. Las Vegas, Nevada: Bechtel SAIC Company.

171539 DOE (U.S. Department of Energy) 2004. Quality Assurance Requirements and Description. DOE/RW-0333P, Rev. 16. Washington, D.C.: U.S. Department of Energy, Office of Civilian Radioactive Waste Management. ACC:

DOC.20040907.0002.

171541 BSC (Bechtel SAIC Company) 2004. Strategies for Recovery from Off-Normal Emplacement and Retrieval Events. 800-30R-HER0-00200-000-000. Las Vegas, Nevada: Bechtel SAIC Company. ACC: ENG.20041118.0021.

171599 BSC (Bechtel SAIC Company) 2004. Project Design Criteria Document. 000-3DRMGR0-00100-000-003. Las Vegas, Nevada: Bechtel SAIC Company. ACC: ENG.20041124.0001.

172171 BSC (Bechtel SAIC Company) 2004. Overall Monitored Geologic Repository Site Layout. 000-C00-MGR0-00101-000-00B. Las Vegas, Nevada: Bechtel SAIC Company. ACC: ENG.20041007.0003.

172452 BSC (Bechtel SAIC Company) 2004. Performance Confirmation Plan. TDR-PCSSE-000001 REV 05. Las Vegas, Nevada: Bechtel SAIC Company. ACC: DOC.20041122.0002. 


\subsection{CODES, STANDARDS, REGULATIONS, AND PROCEDURES}

15660510 CFR 63. Energy: Disposal of High-Level Radioactive Wastes in a Geologic Repository at Yucca Mountain, Nevada. Readily available.

15667166 FR 55732. Disposal of High-Level Radioactive Wastes in a Proposed Geologic Repository at Yucca Mountain, NV, Final Rule. 10 CFR Parts 2, 19, 20, 21, 30, 40, 51, 60, 61, 63, 70, 72, 73, and 75. Readily available.

LP-3.11Q-BSC. Technical Reports.

LP-SI.11Q-BSC. Software Management. 


\section{INTENTIONALLY LEFT BLANK}

